\title{
THE ROLE OF THE TECHNOLOGICAL REVOLUTION IN THE DEVELOPMENT OF EGYPTIAN CITIES AND THE EMERGENCE OF NEW TYPES OF CITIES (CASE STUDY CITY OF 10TH OF RAMADAN)
}

\author{
Mohiy Fayed Mohiy EL Ganzoury, Mohamed S. Atoa and Ahmed A. EL Kttan \\ Department of Architectural Engineering, Faculty of Engineering, AL Azhar University
}

\begin{abstract}
ABASTRACT
The rapid development of the information revolution has had a significant impact on daily life, the city's pattern and its urban centers. The city in the 21 st century is highly dependent on informatics in all life activities. This has led to the emergence of a new type of enterprise called smart urban projects. A new vision of the urban development process of these cities, smart urban projects and newly created areas, and should be directed to the attention of planners and planners of urban planning and the processes of urban development of existing and new cities to a serious dimension $\mathrm{D}$, which imposes itself firmly on the pattern of life and the development process in the future, namely the information revolution. The technological and informational revolution, which is expected to affect the design and planning of smart projects, is also expected to have a significant impact on life and the city in the future and is expected to have a significant impact on the urban planning process of the future city and affect all components of the urban development process. In this research, the city is dealt with in the information age, starting with its infrastructure and the types of modern cities. It then deals with the different components of the information city, which is the material, environmental, social and economic component. The chapter then deals with the changes that take place in the information age and the subsequent reconstruction of the urban structure Allowing the planner and urban designer urban integration between the environment and society and individual in accordance with the rapid changes of modern technologies that occur in our world continuously.
\end{abstract}

Keywords: Technology City / Smart City / Informatics City / E- City / Urban Development / Sustainable Communities$$
\text { دور الثورة التكنولوجية في تتمية المدن المصرية وظهور أنواع جديدة من المدن منان }
$$

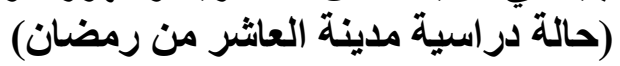$$
\text { محمد سعد عطوة وأحمد عبد المنعم القطان و محيبي فايد محيي الجنزوريو }
$$$$
\text { قسم العمارة كلية الهندسة ـ جامعة الأز هر ـ القاهرة }
$$

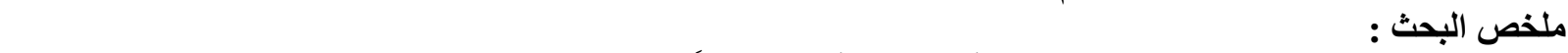

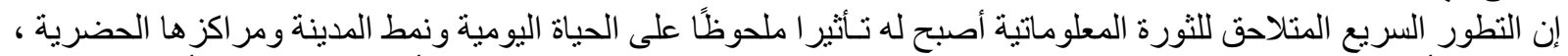

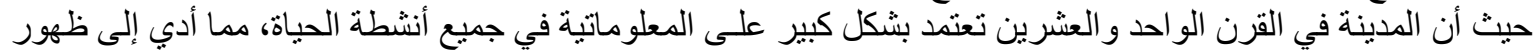

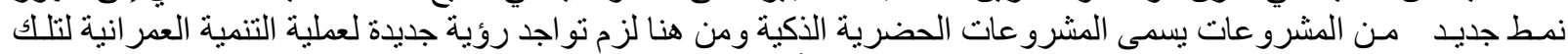

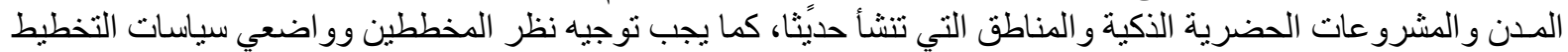

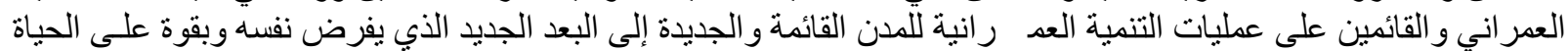

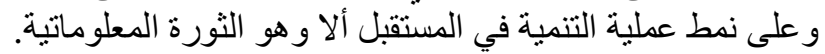




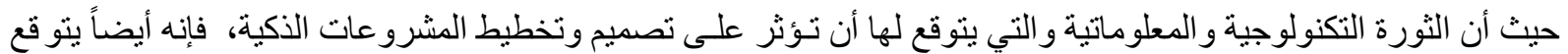

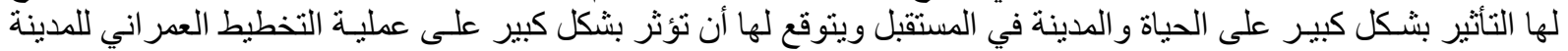

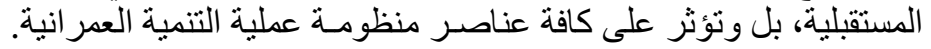

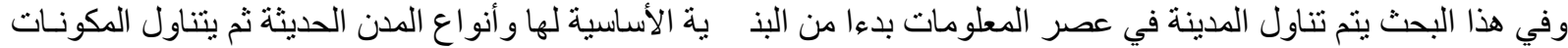

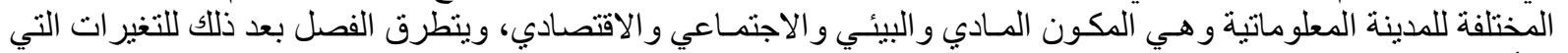

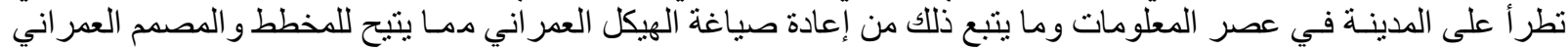

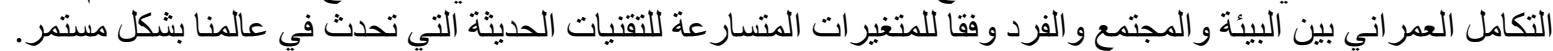

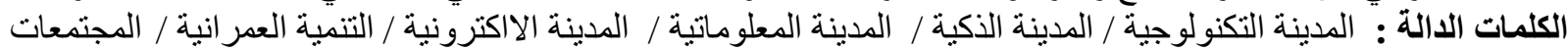

المستدامة ماتمة

مقدمة :

لقد أثر الـ تطور العلمي في الكثير من المفاهيم و المعايير التخطيطية والتصميمية للعناصر العمر انية، وكمثال على ذلك التطور

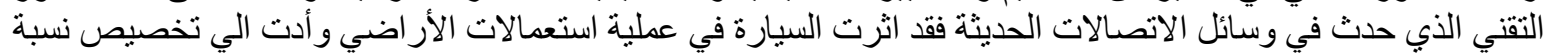

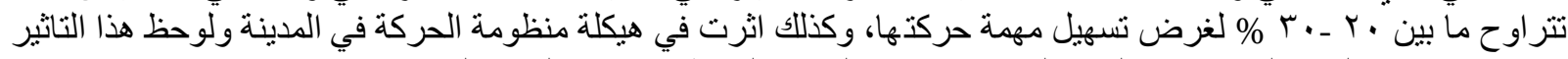

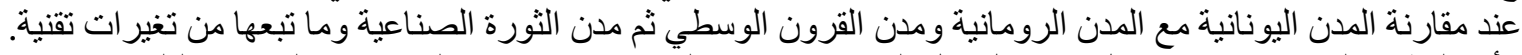

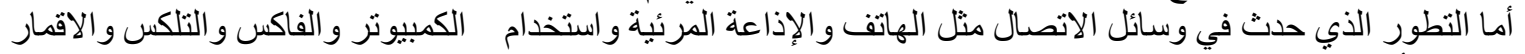

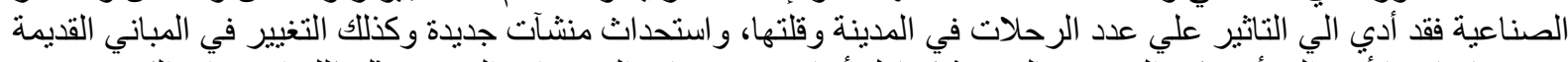

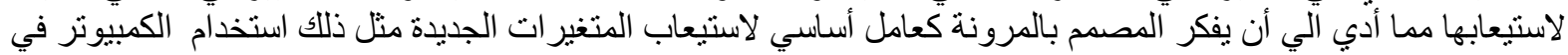

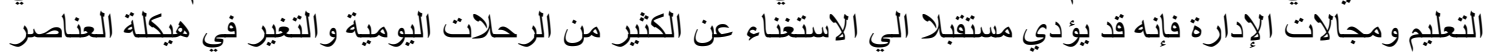

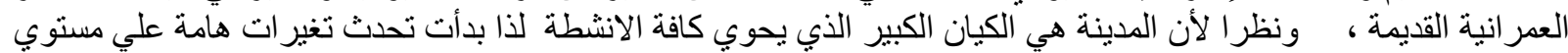

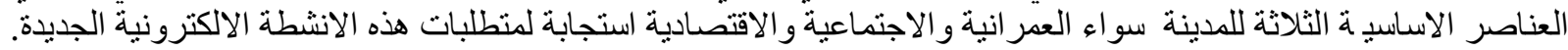

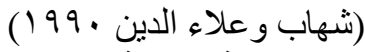

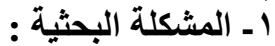

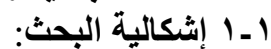

تكمن إثكالية البحث في توجيه الضوء علئ علي تكنولوجيا المعلومات و أثره في تطوير المدن وحل المشاكل الموجودة بالمدن القائمة

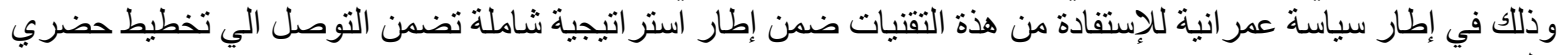

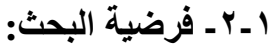

يري البحث أن التطور التكنولوجي له الأثر الكبير في التغير ات التي تطر أ علي المدينة وذلك من خلال التغير في الموقع المكاني

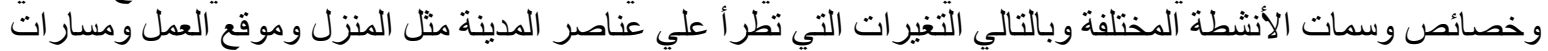

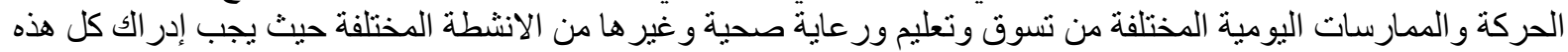
المتغير ات في إطار التعرف علي الأنواع المختلفة للمدن التي ظهرت بلتئن بعد الثورة التكنولوجية.

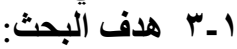

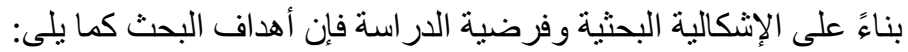

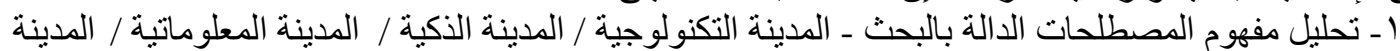

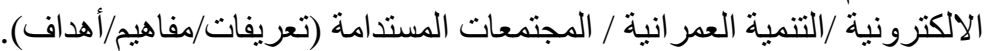

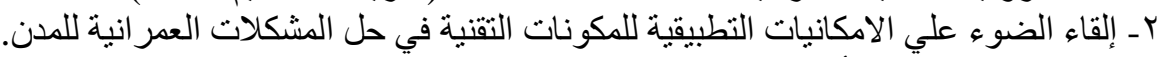

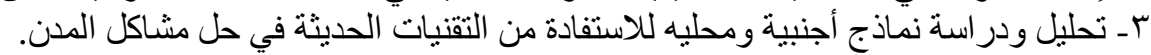

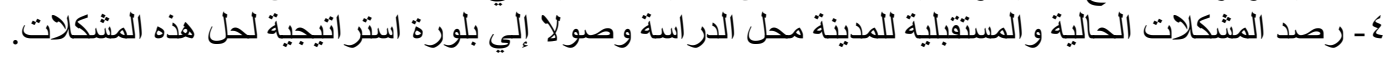

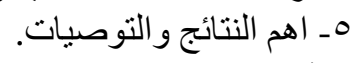

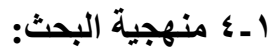

لتحقيق الأهداف السابقة يتبع البحث المنهج النظرى التحليلى و منهج الرصد الميدانى كأسلوب بحثى ، و تم بو اسطة تحديد ثلاث

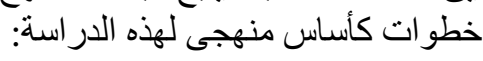
1 - المنهج النظري التحليلى:

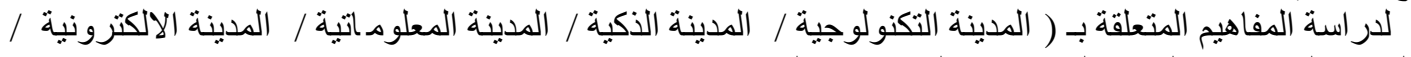

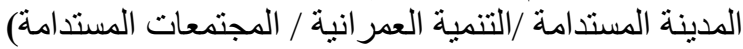

در اسة خصائص و إمكانيات أنواع المدن المخته المنلفة السابق ذكر ها. 
دراسة التغير ات في انواع الانشطة والممارسات وعناصر المدينة نظر اللتطور التكنولوجي.

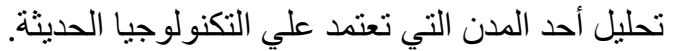

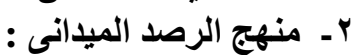

در اسة وتحليل عناصر المدينة محل الدر اسة ورصد للمشكلات و أنو اع الانشطة الممارسة بها.

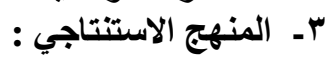

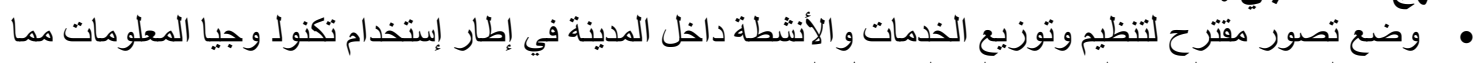

بساعد على تحقيق التنمية العمر انية الثناملة داخل التهات المدينة.

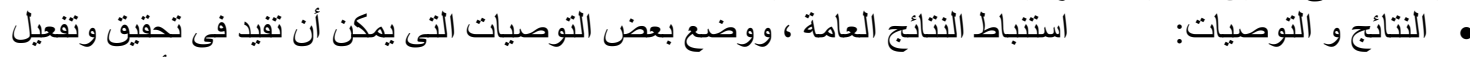

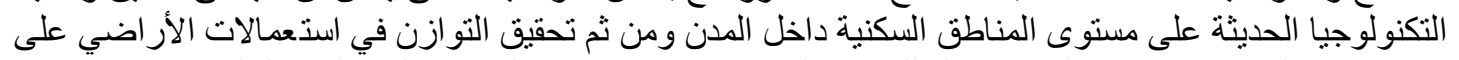

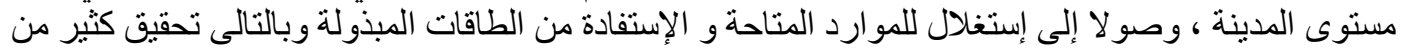

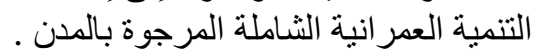

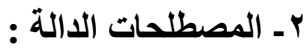

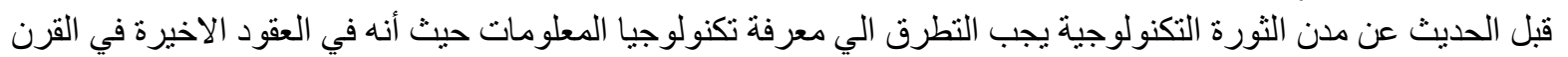

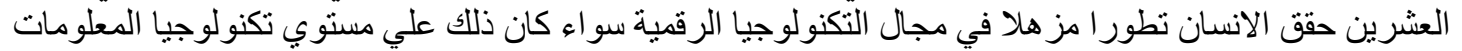

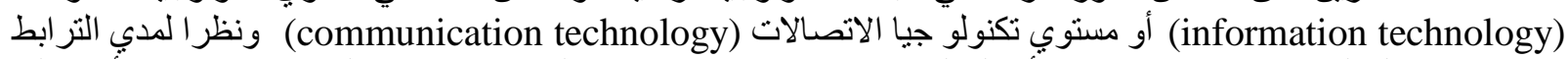

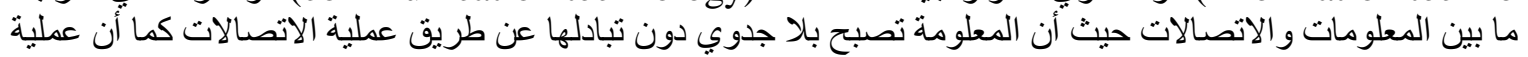

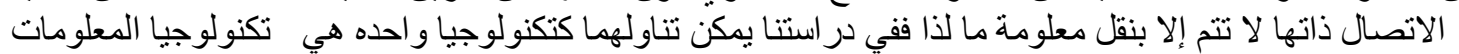

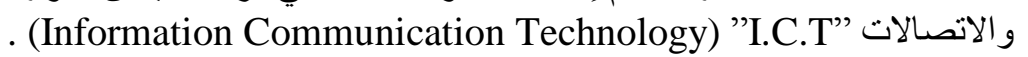
وتتمثل التكنولوجيا في مكونين أساسيين:

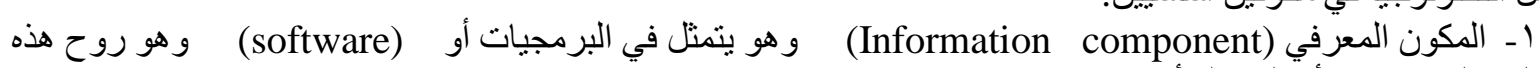
التكنولوجيا حيث أنه ليس له أبي وجود مادي.

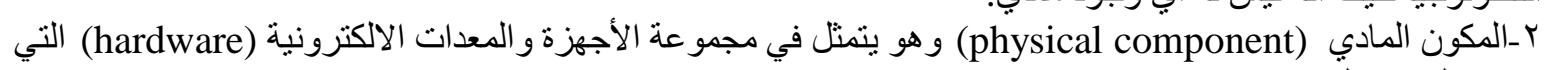

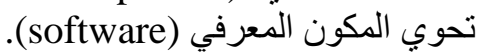
اتجاهات تطوير تكنولوجيا المعلومات المبرون

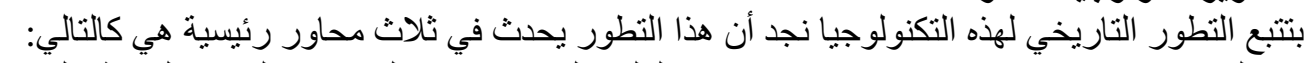

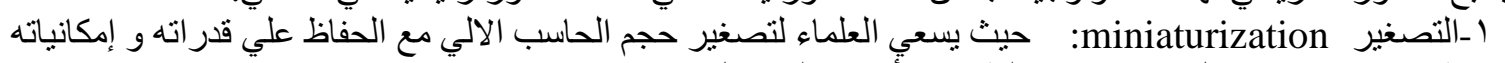

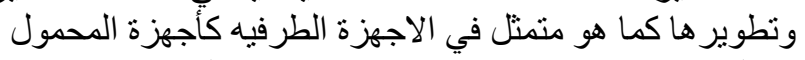

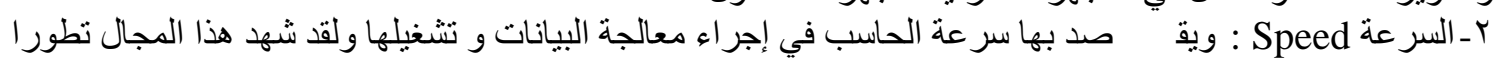

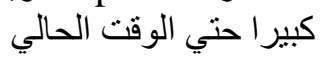

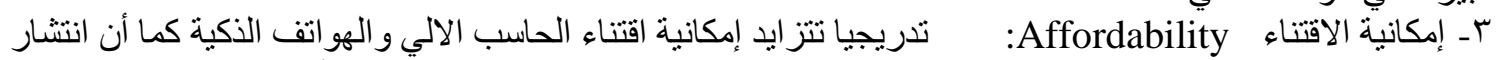

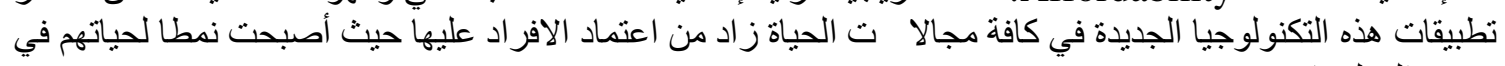

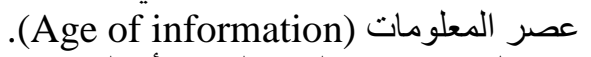

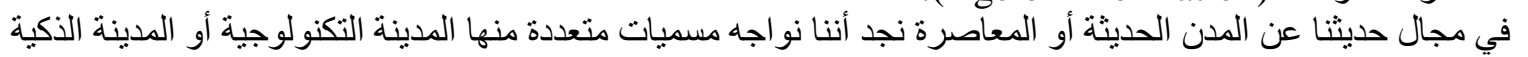

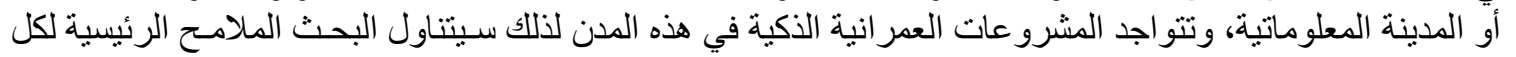

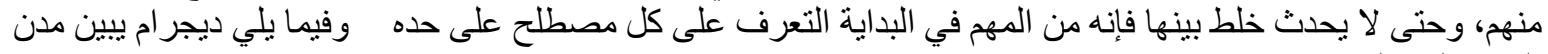

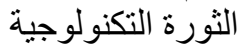

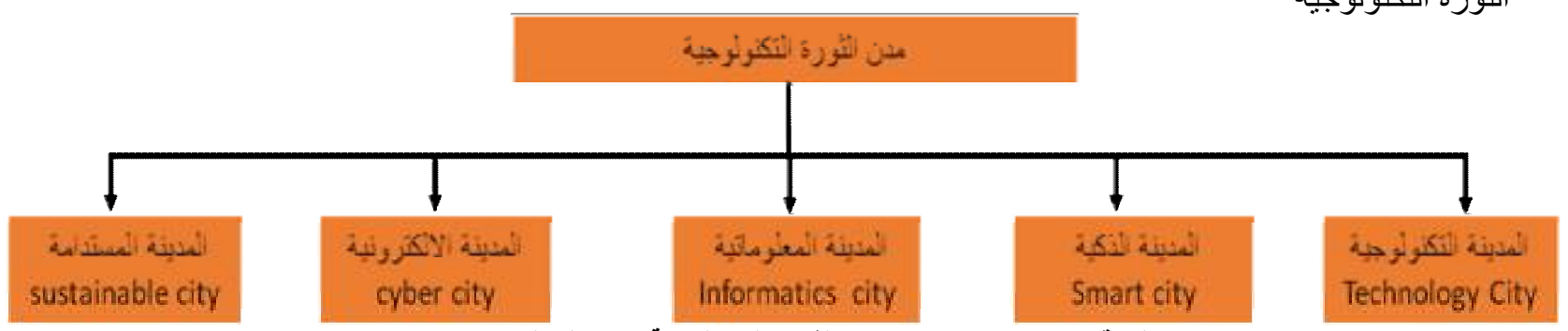

شكل رقم ( ) ديجرام يوضح مدن الثورة التكنولوجية (بتصرف الباحث) 
Technology City المدينة التكنولوجية الكوجية

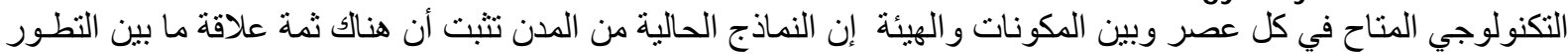

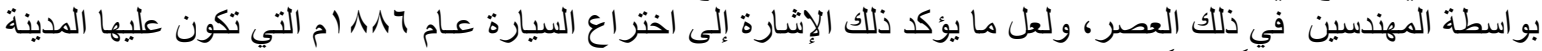

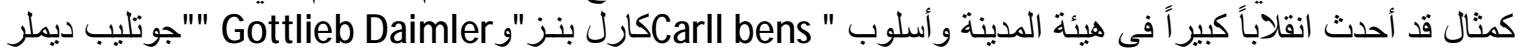

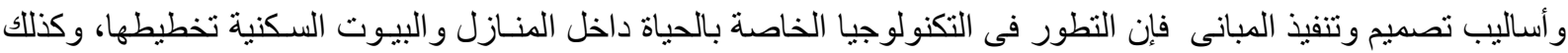
ووضع المبانى فى المناطق السكنية و الخدمية، وبالتالى التأثير على المدينة بشكل مثل ناطحات السحاب، قد انعكس على شكل

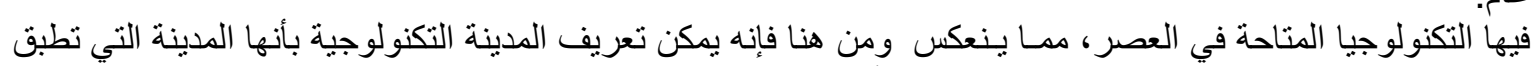

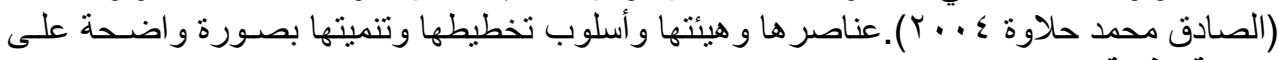

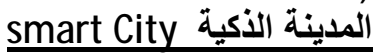

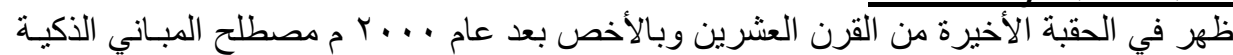

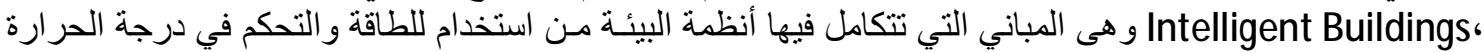

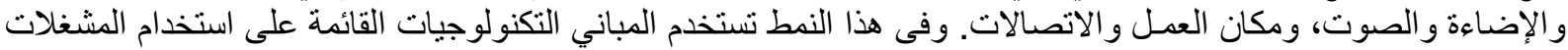

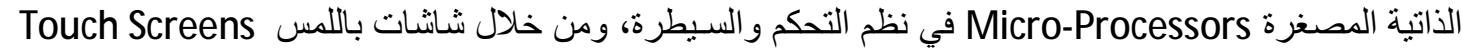

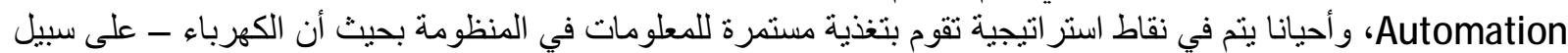

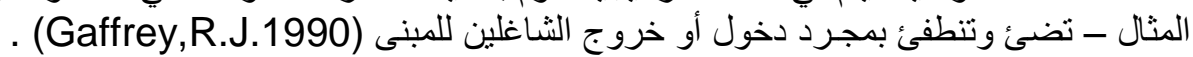

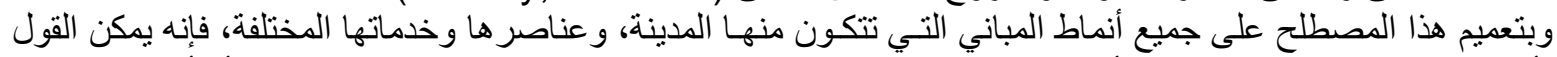

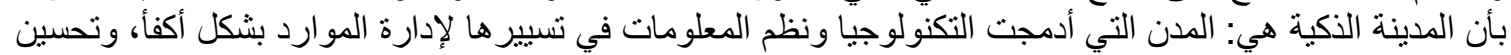

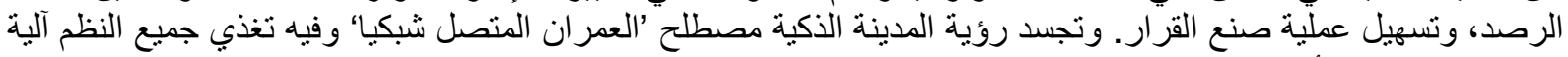

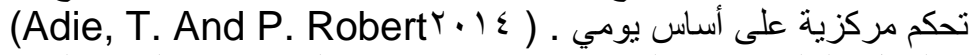
و الثنكل التالي يوضح العلاقة بين بعض الانظمة الرئيسية في المدينة الذكية

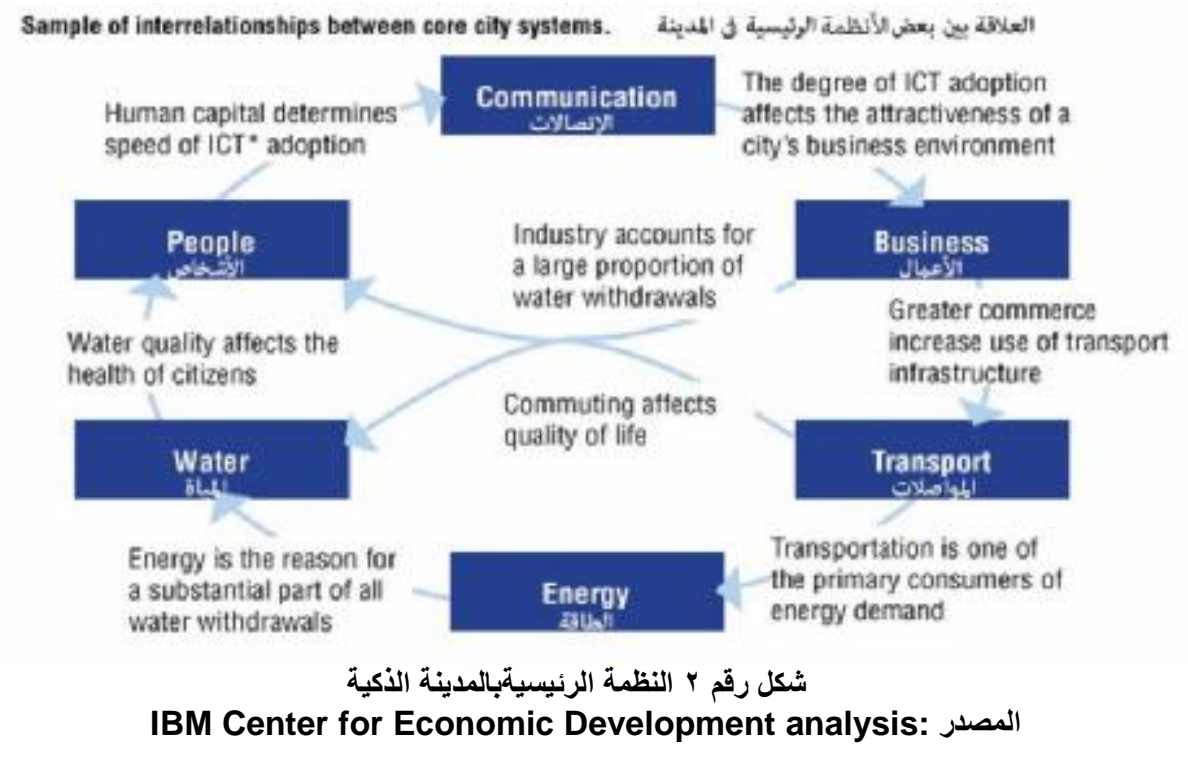

وتتميز المدينة الأكية بما يلي: تلئي

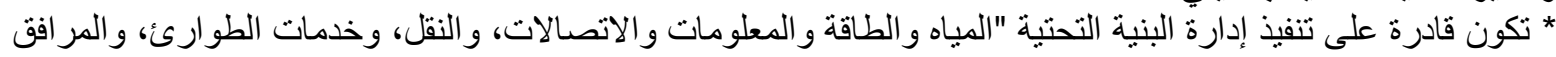

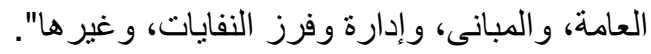

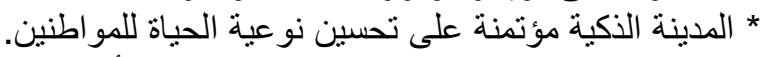

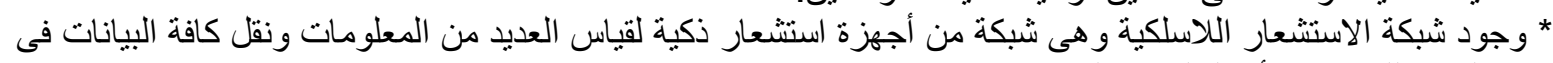
نفس الوقت للمود اطنين أو السلطات المعنية. 
يمكن القول أن مصطلح المدينة المعلوماتية هو مصطلح مركب، فقد يعنى في بعض جو انبه أنها المدينة التكنولوجية عندما

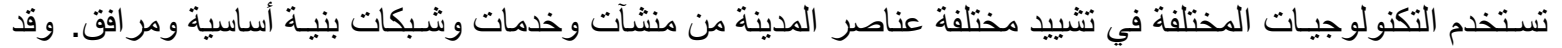

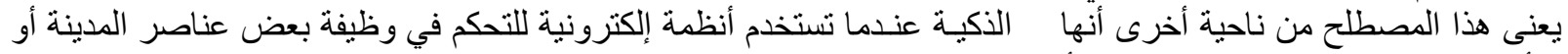

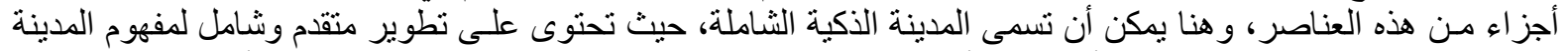

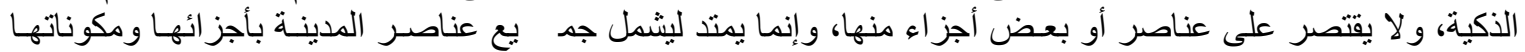

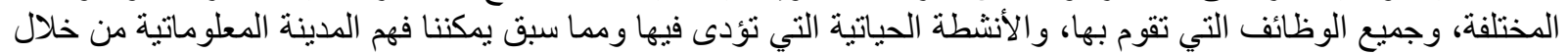

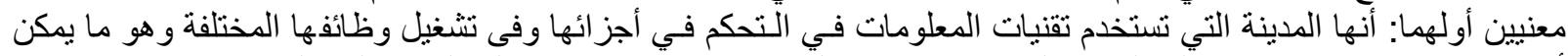

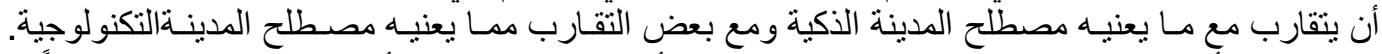

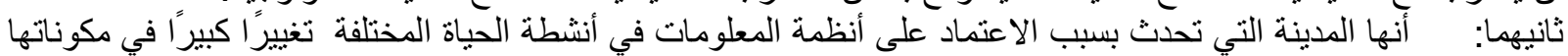

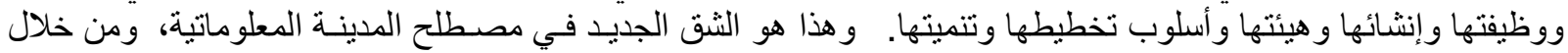

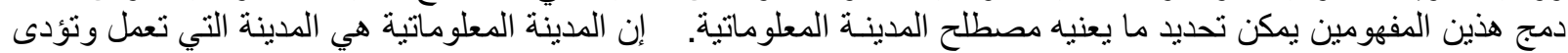

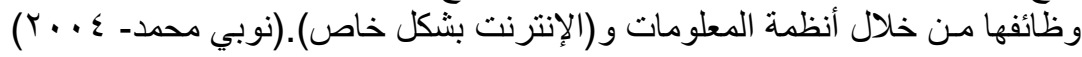

Cyber City

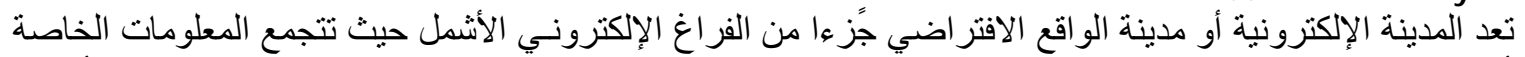

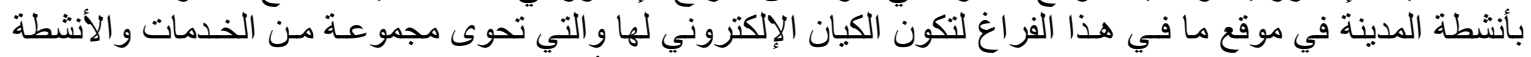

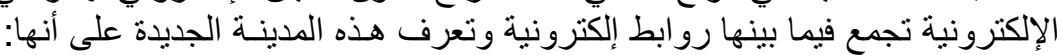
a real physical city) (Virtual Cities that perform functions parallel to those of.

(http://www.geog.ucl.ac.uk)

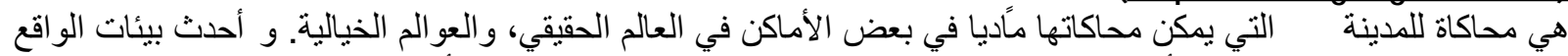

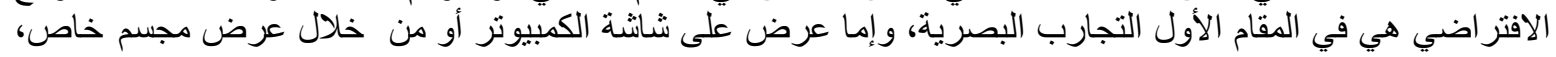

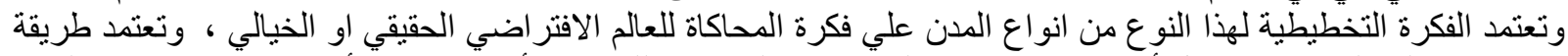

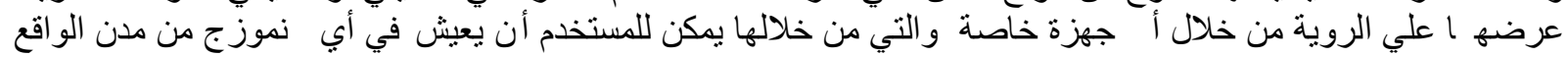

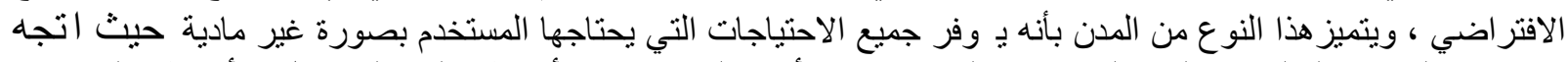

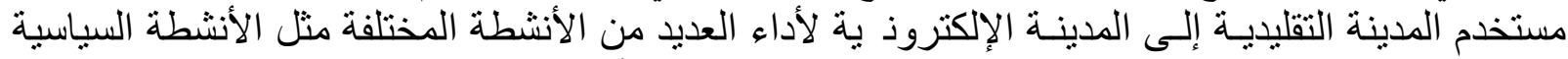

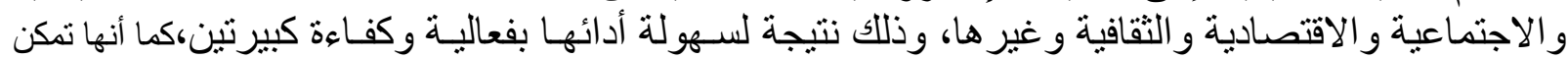

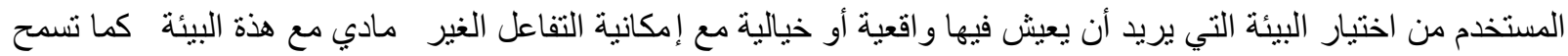

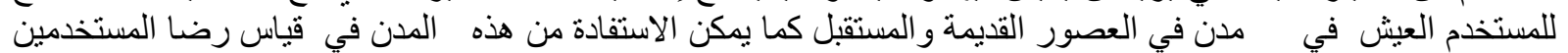

و التفاعل مع المدن الجديدة قبل إنشائها . Sustainable City

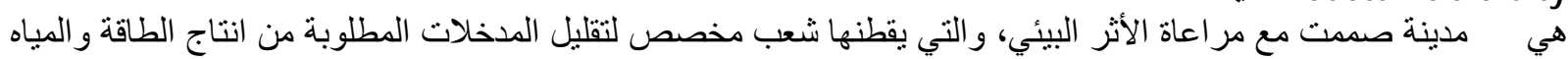

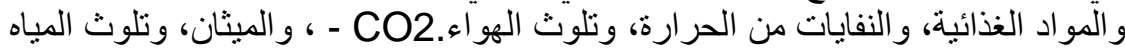
(مدينة_مستدامة

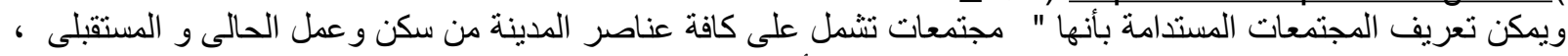

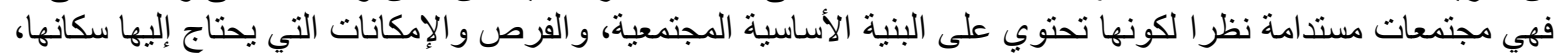

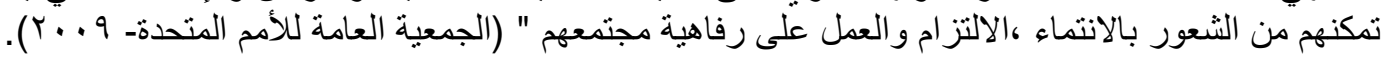

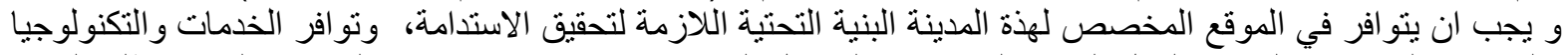
المتقدمة بالقرب من المدينة ولعمل المدينة المستدامة والتوصل الي مجتمعات مـ ستدامة يجب التعرف التئة علي مصطلح التتمية المستدامة المبلة

فالتنمية المستدامة هى " إستر اتيجية تسعى بو اسطتها المجتمعات الإنسانية لتطوير سياستها التتموية ( الإقتصادية و الإجتماعية

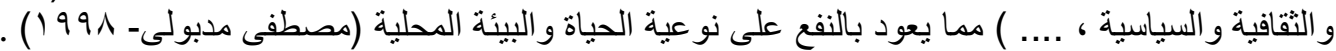

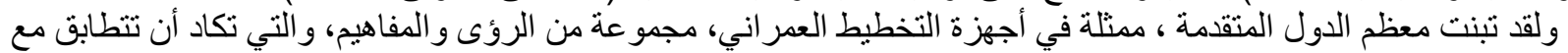

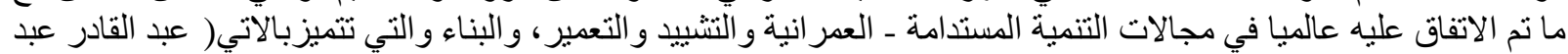

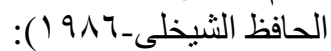

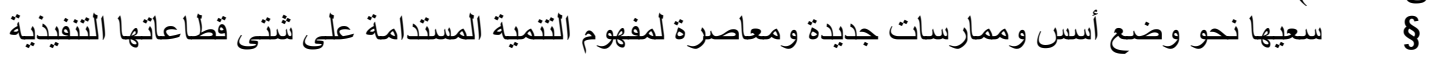
و التشريعية تمكنها من مو اجهة تحديات الحاضر وتوقعات وتطلعات ونسات المستقبل. 
سعيها لإنثاء المجتمعات المستدامة ، وإعادة تطوير وتأهيل المناطق الحضرية و الريف ية والتر اثثية التقليدية ،

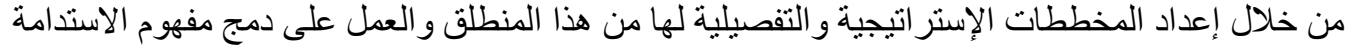

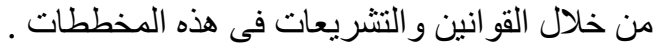

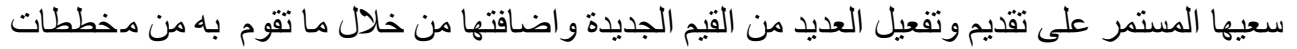

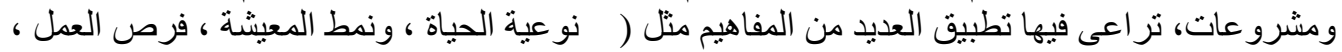

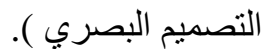

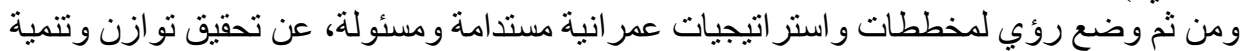

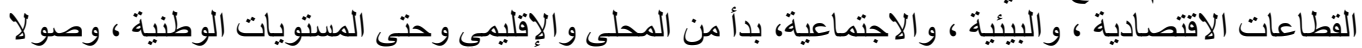
إلى أدق تفاصيل التصميم العمر اني .

خصائص مدن الثورة التكنولوجية

تتميز مدن الثورة التكنولوجية سو اء التكنولوجية او الزكية او المستدامة أو المعلوماتية بالخصائص التالية كما يوضح

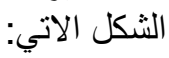

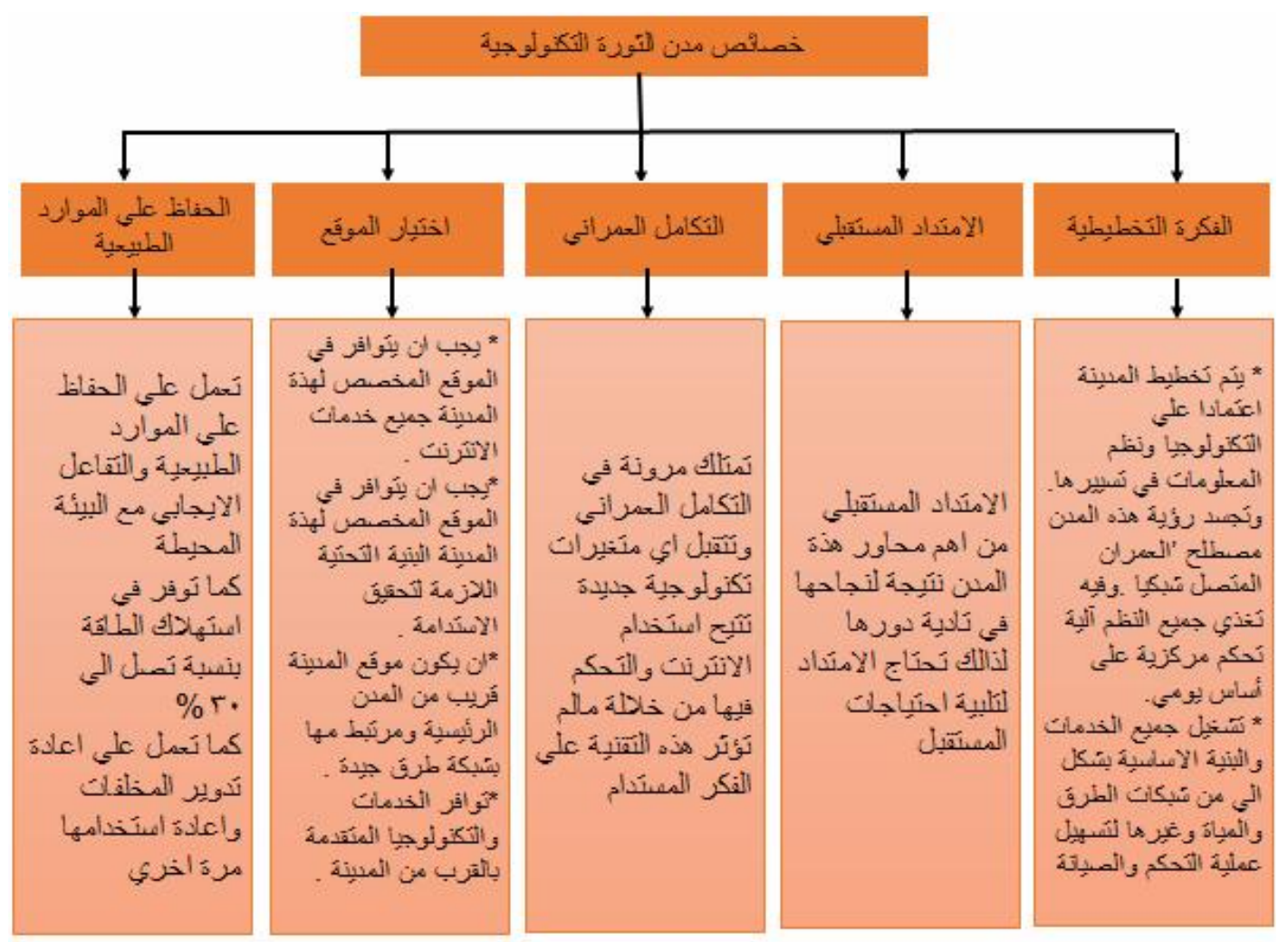

التفييرات التي تطر أ على المدينة في عصر المطلومات:

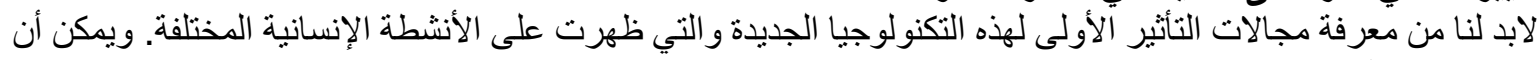

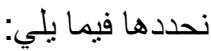

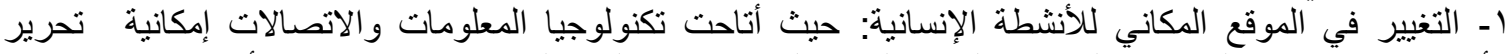

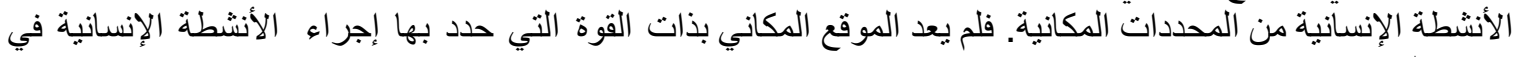
عصر الصناعة

(Character): فكلما أثرت التكنولوجيا الجديدة على الموقع المكاني

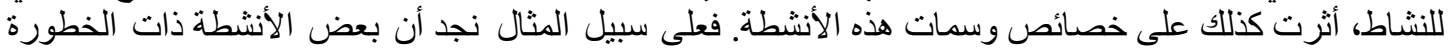

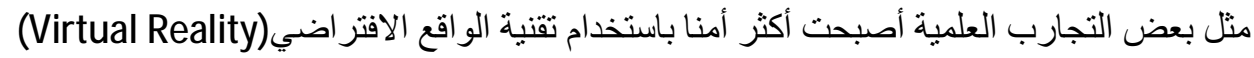




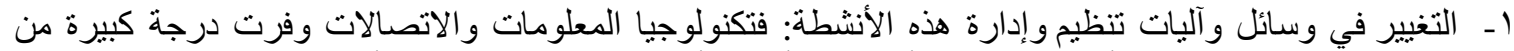

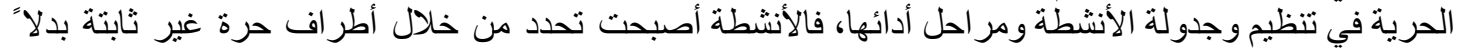

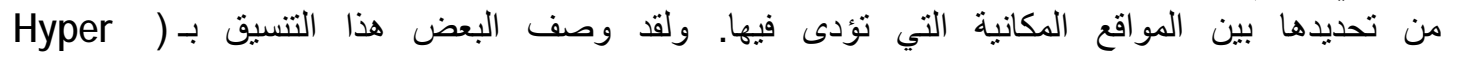
(Coordination وقبل أن نبدأ بدراسة وتحليل تأثثير التكنولوجيا الحديثة على المدينة يجب التعرف على علي أهم مظاهر التحول والتغيرات التي طر أت على بعض نبل عناصر المدينة.

التحول الذي طرأ على عناصر المدينة (المنزل - موقع العمل):

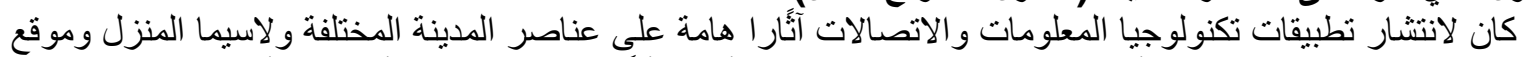

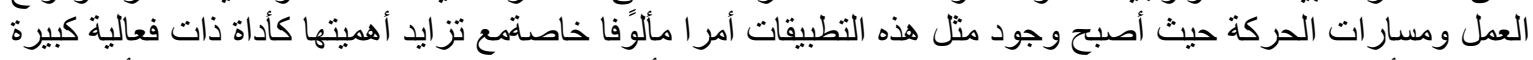

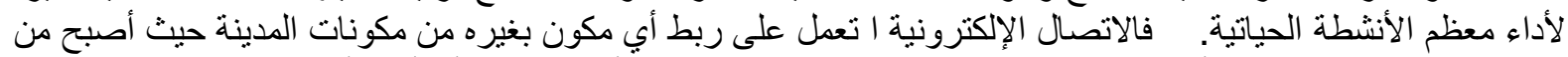

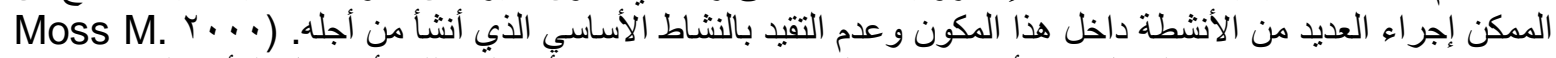

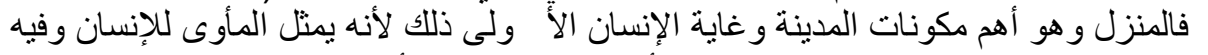

(\& Townsend A.

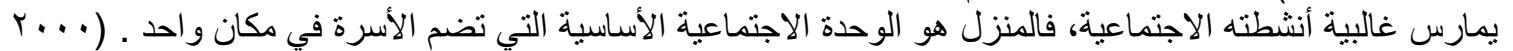

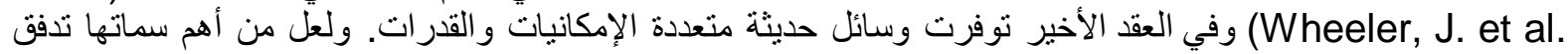

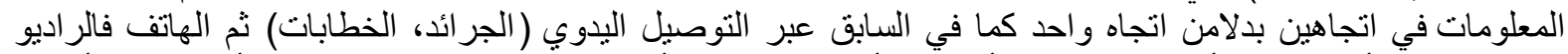

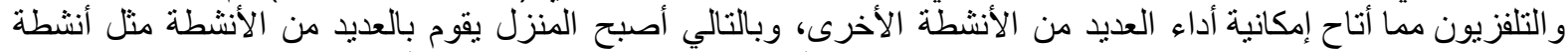

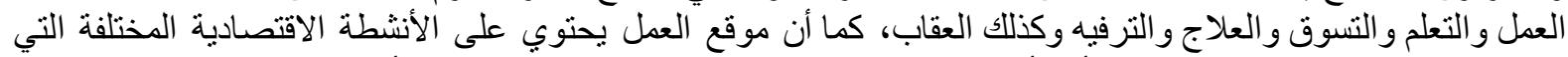

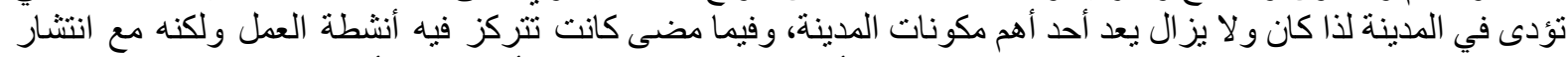

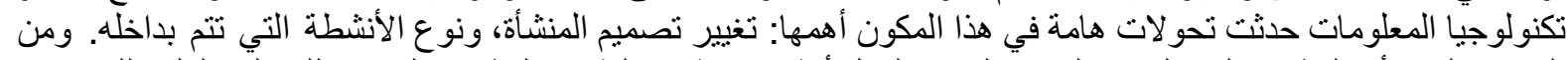

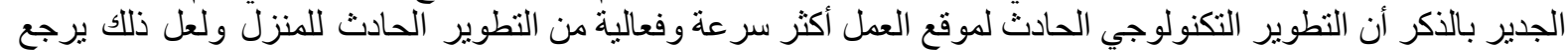

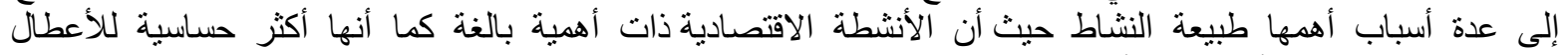

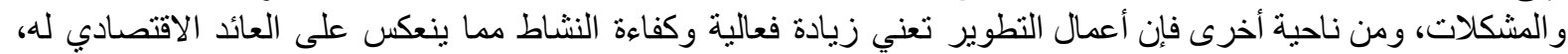

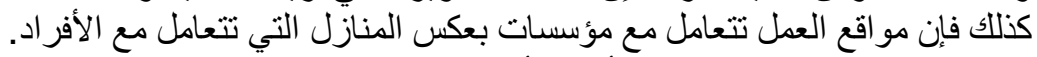

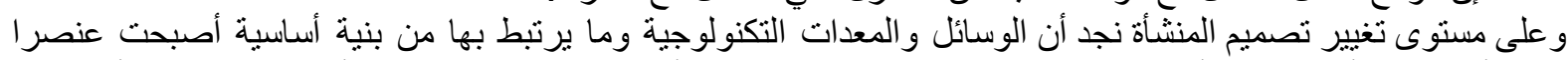

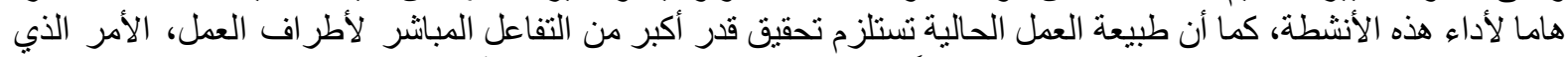

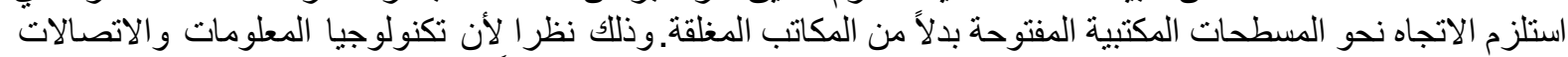

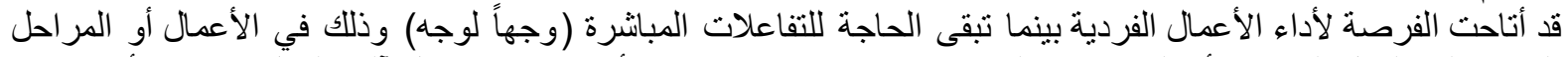

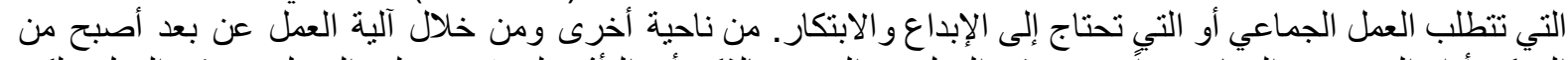

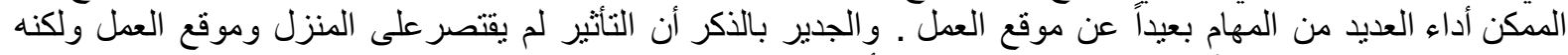

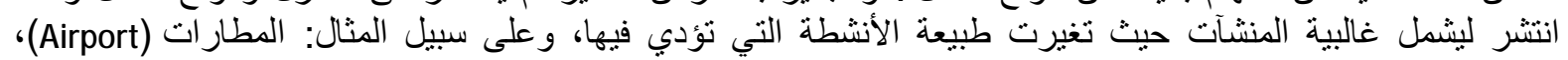

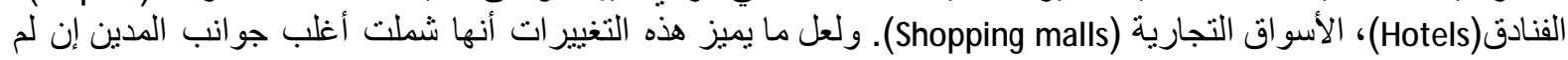
(http://www.informationcity.org) يكن جميعها.

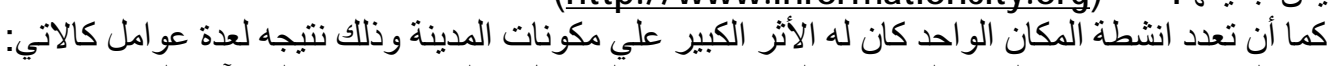

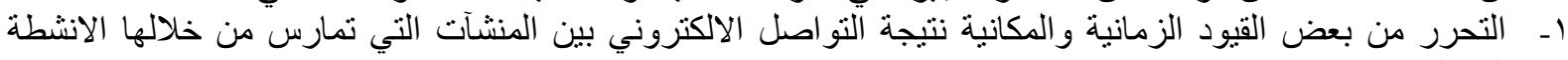
المختلفة.

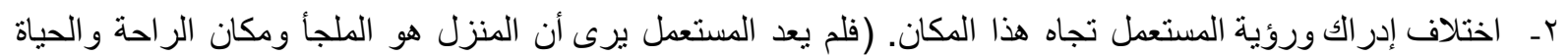

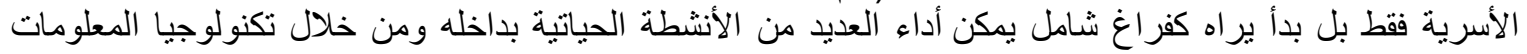

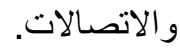
بـتأثر الهيكل الاجتماعي للمدينة حيث تغيرت العلاقات الإنسانية والاجتماعية بين المستعملين كما تأثر التكوين الاجتماعي ع ـلم تعد المنشآت على علاقة بمحيطها العمر اني فحسب بل أصبح هناك اهتمام أكبر بعلاقتها بالمحيط الإلكتروني وكيفية تعد منظومة

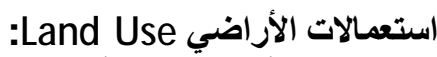

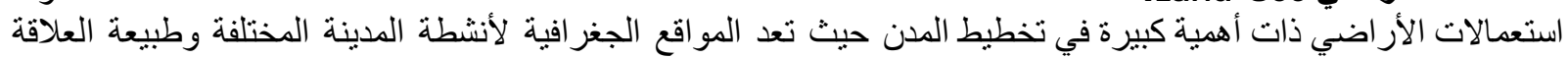

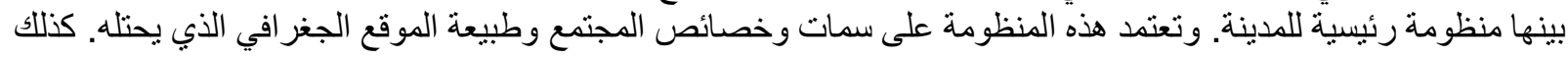


تتغير هذه المنظومة مع اختلاف التكنولوجيا السائدة فقي عصر الزر اعة كانت الاستعمالات متداخلة و لا يحكمها نظام محدد بينما

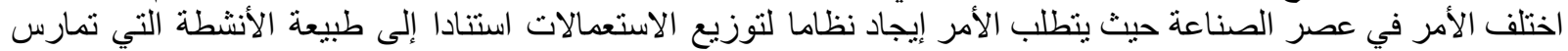

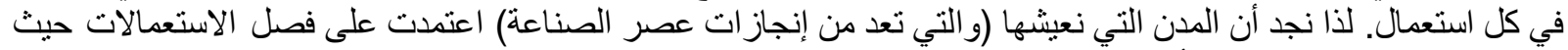

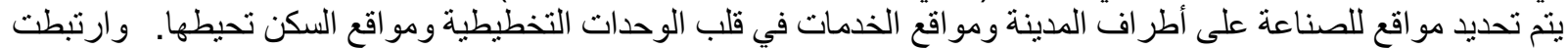

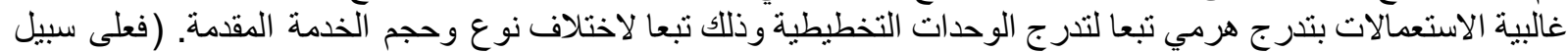

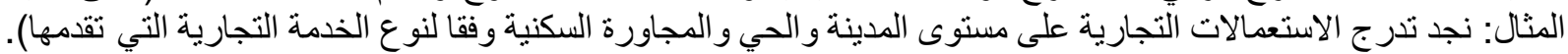

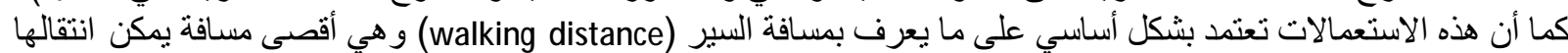

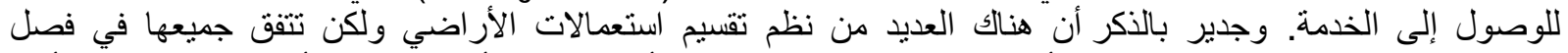

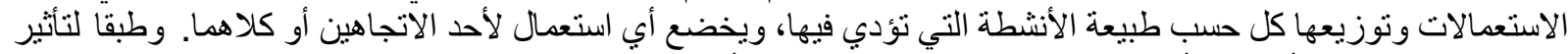

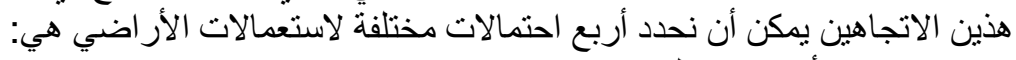

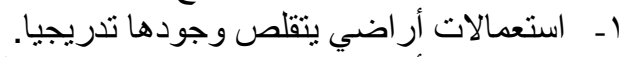

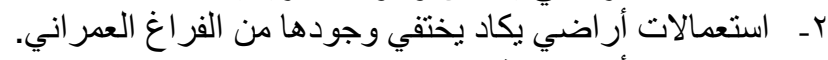

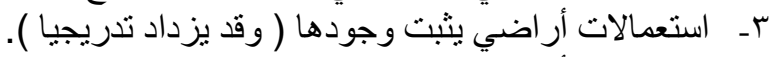

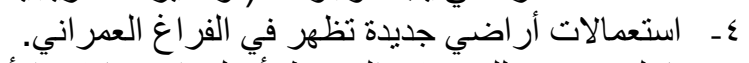

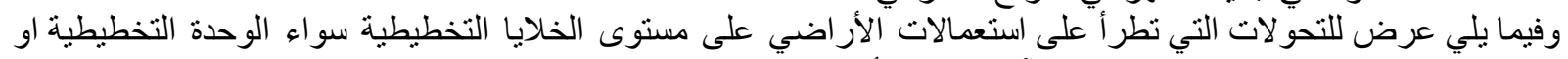

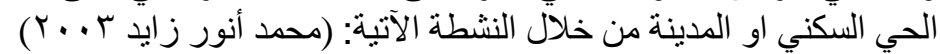

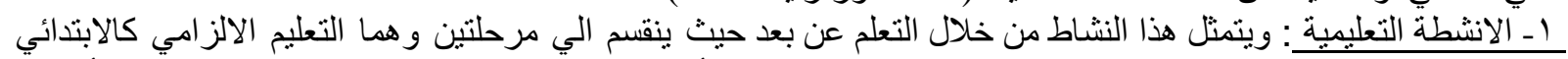

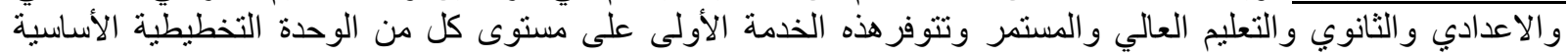

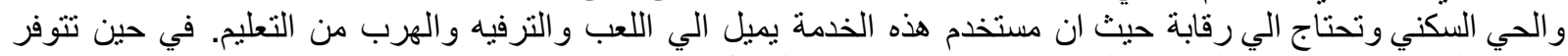

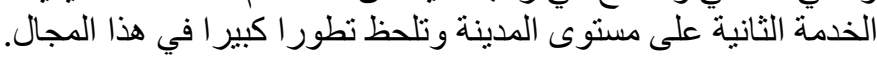

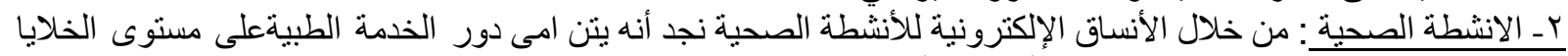

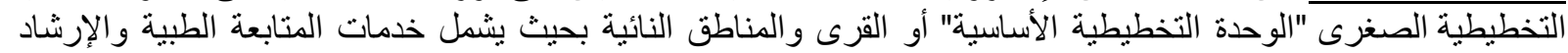

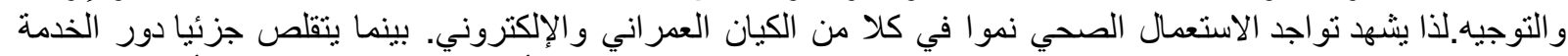

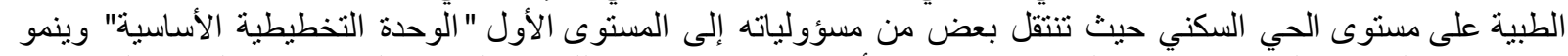

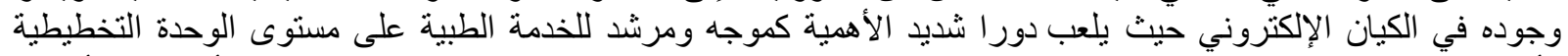

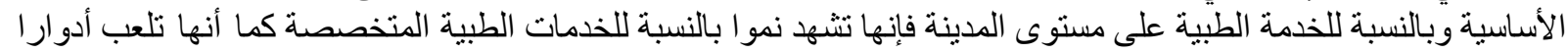

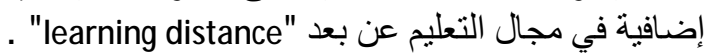

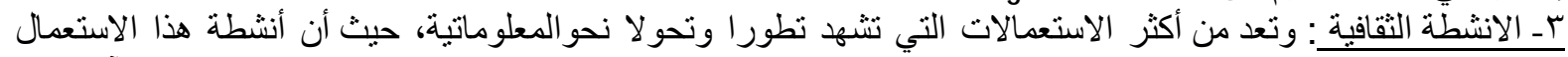

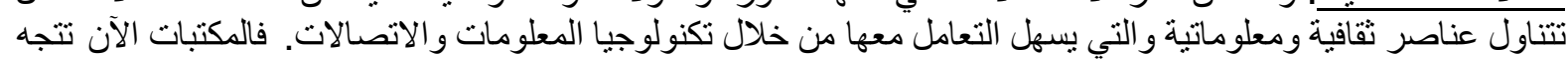

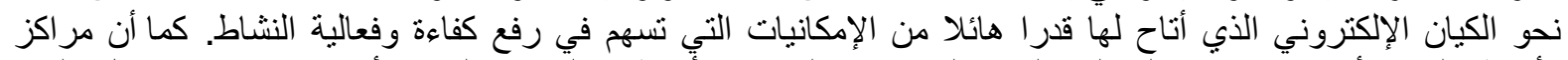

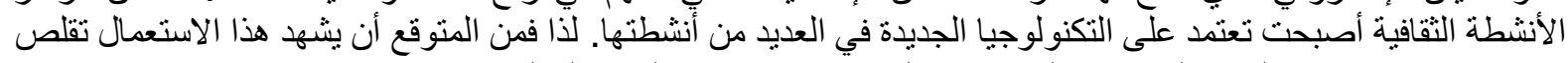

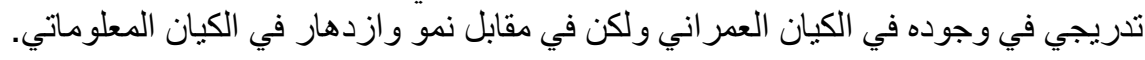

كــ الانشطة التجارية: و وتتمثل في الثراء عبر الانترنت ولكن هذا النشاط يزداد علي مستوي الوحدة التخطيطية نظرا

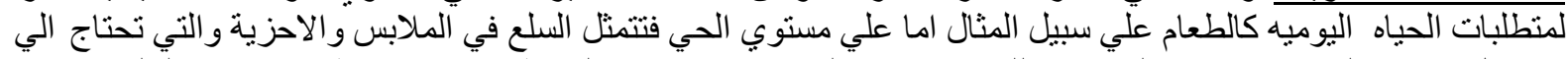

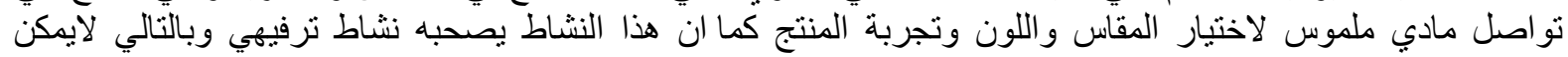

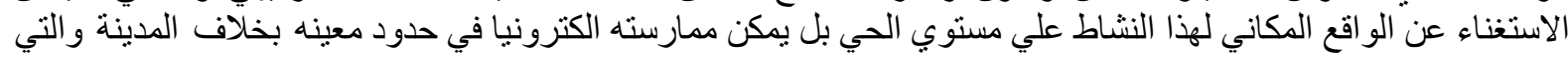

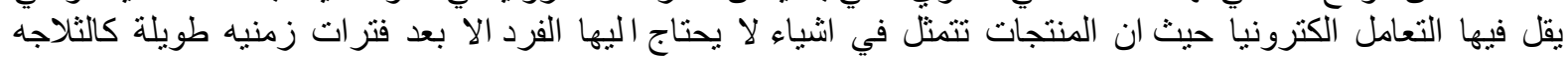

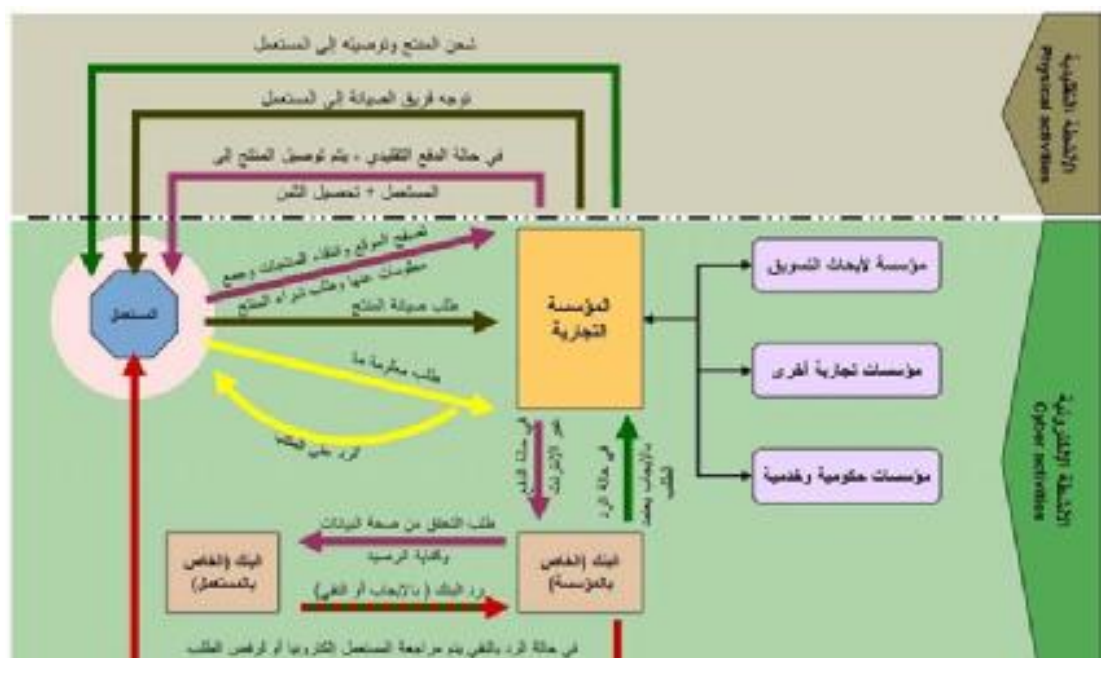

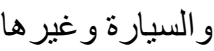


Stefan Probst, "Brief introduction to e-commerce", Vitnam, 1999. : المصدر

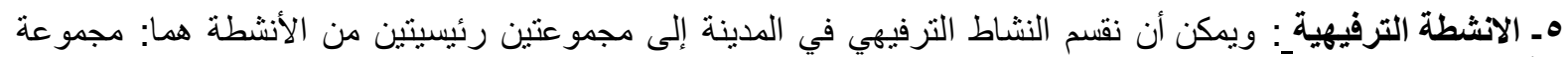

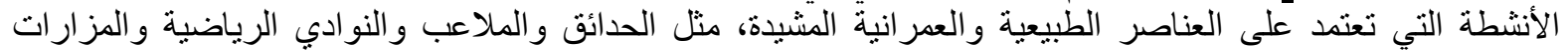

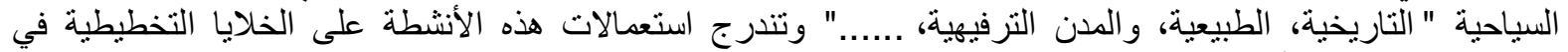

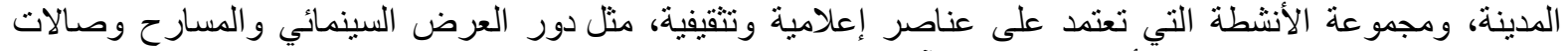

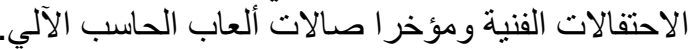

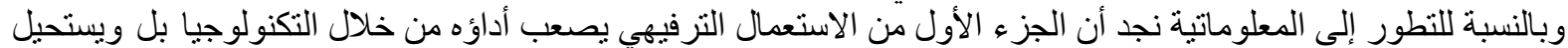

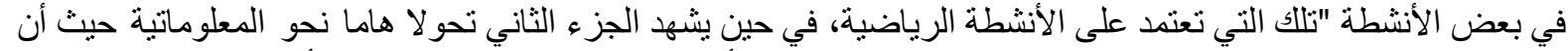

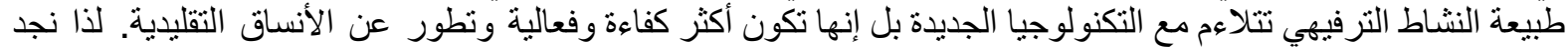

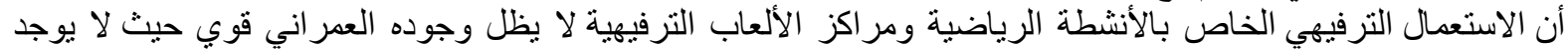

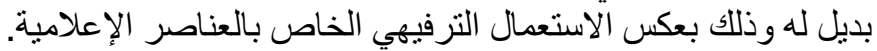

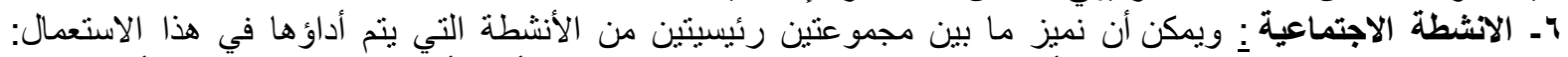

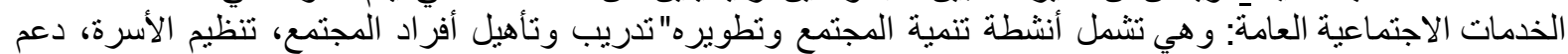

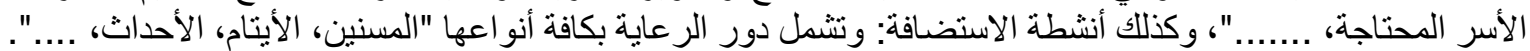

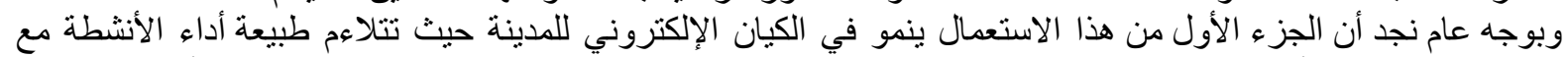

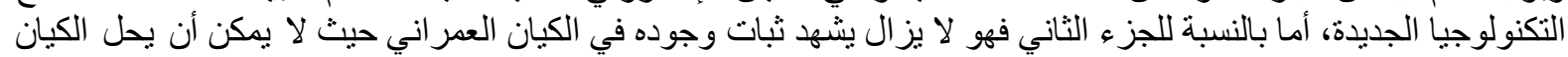

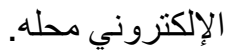

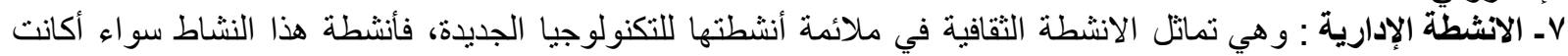

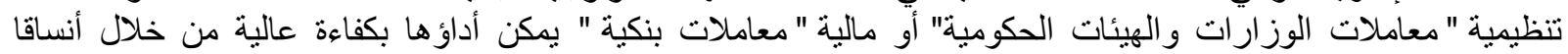

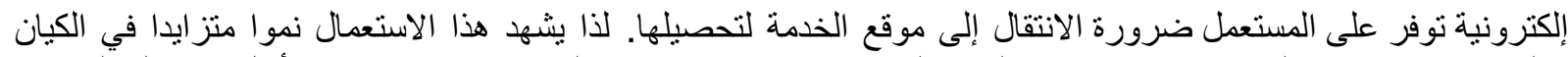

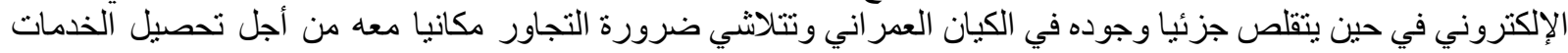

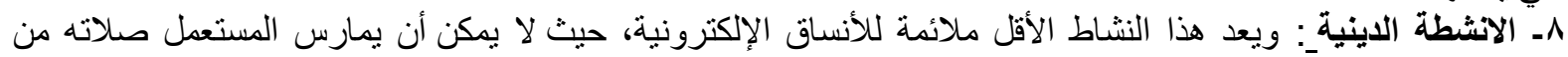

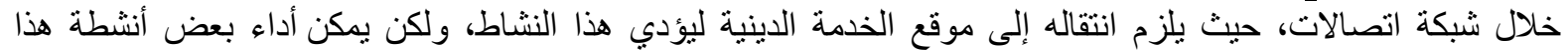

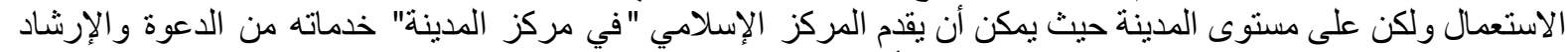

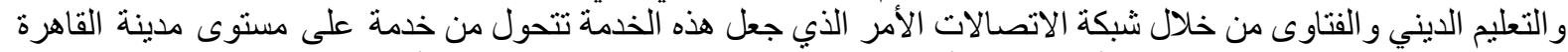

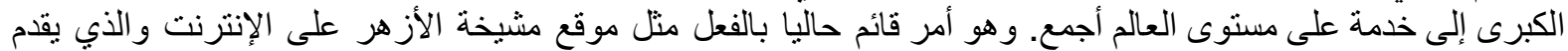

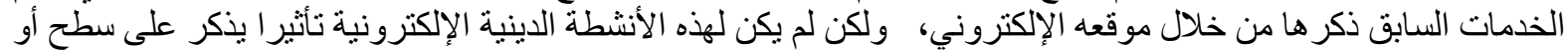

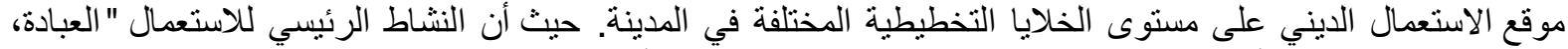
الصلاة" لا يز ال يؤدي بأنساقه التقليدية و التي لا يمكن للتكنولوجيا التيا الحديثة أن تحل محلها.

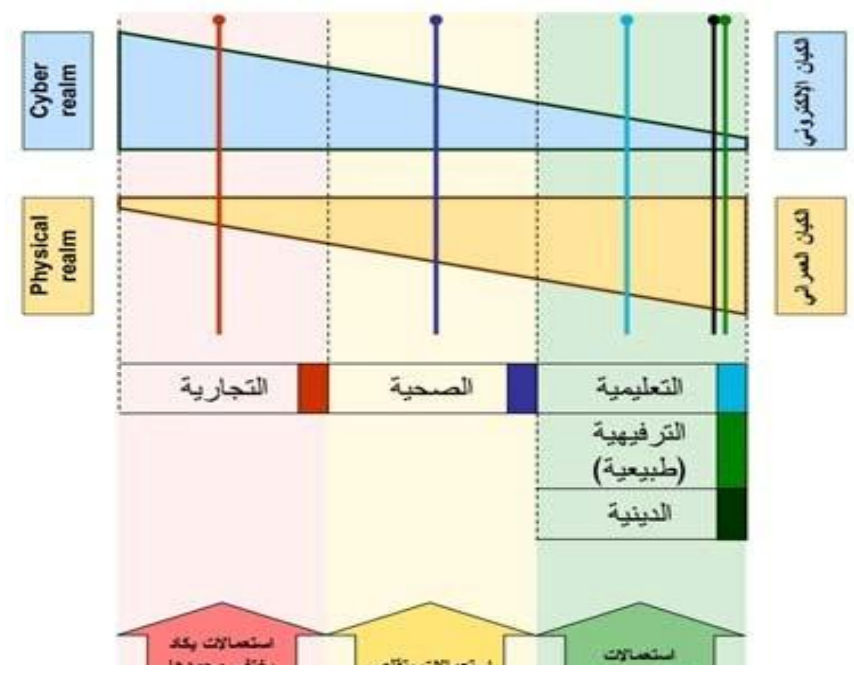




\section{مثال لمدينة تعتمد علي تكنولوجيا المعلومات والاتصالات}

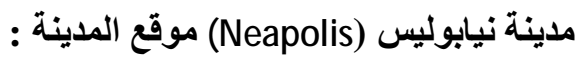

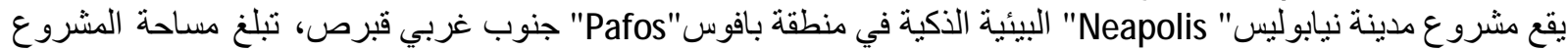

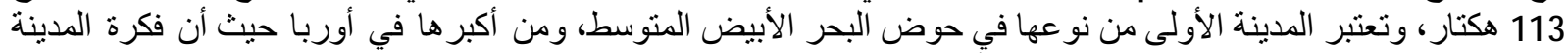

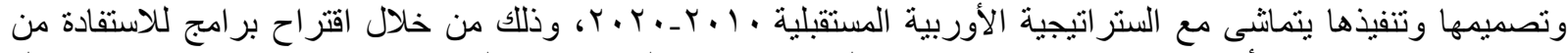

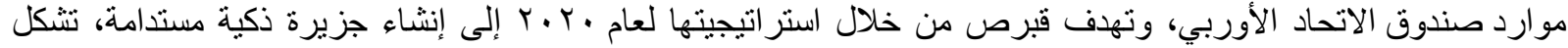

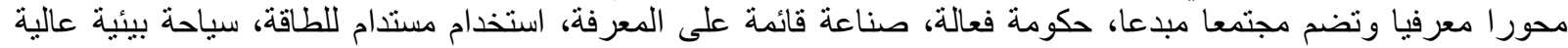

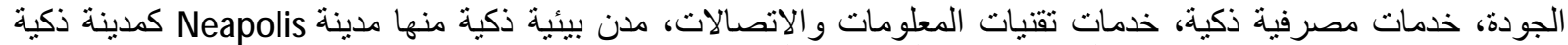

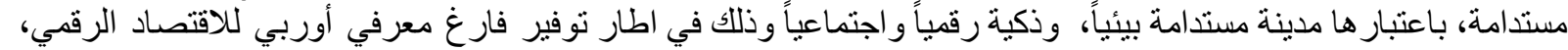

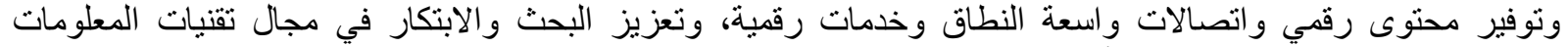

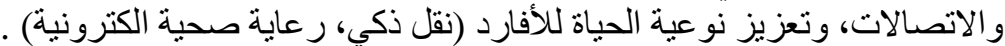

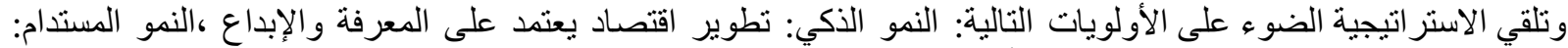

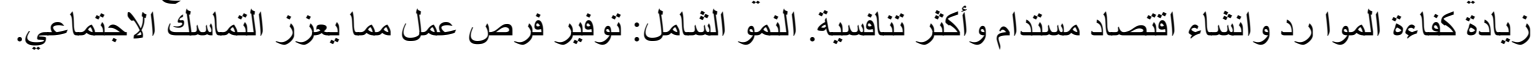

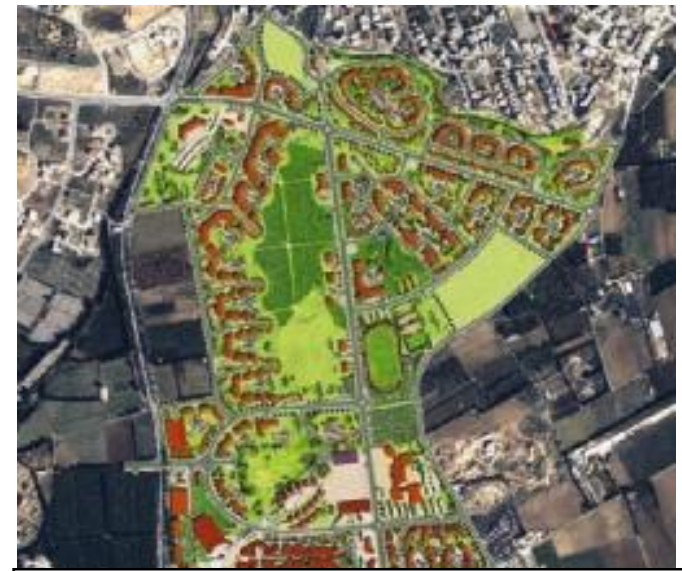

" Neapolis " " "9كل (9): الموقع العام لمدينة نيابوليس المصدر: http://www.neapolis.com

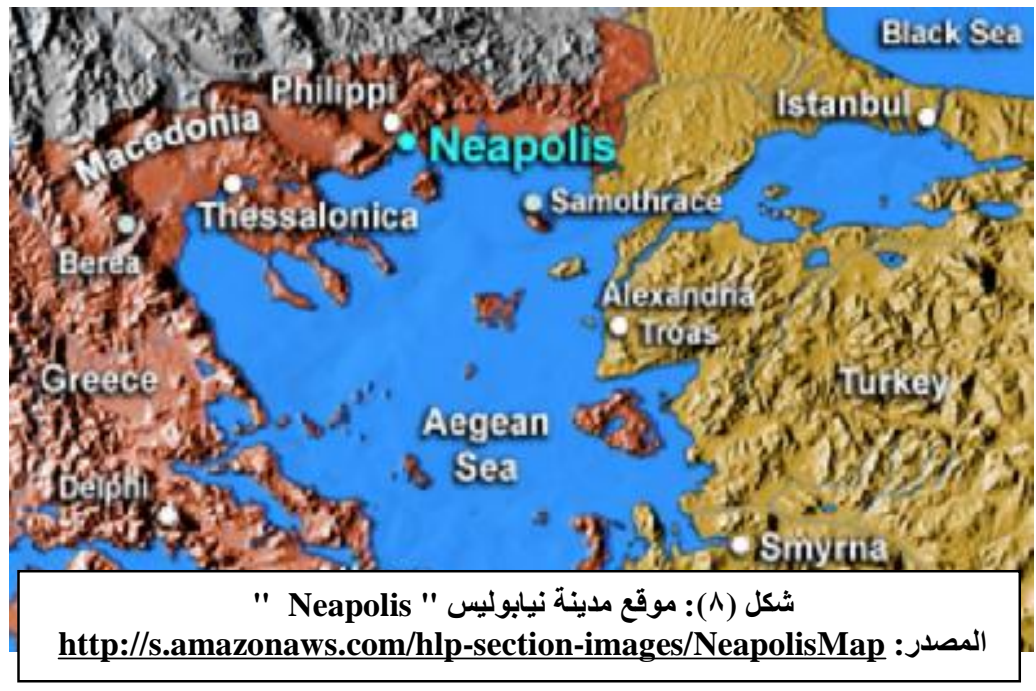

مكونات المدينة : ت مينة

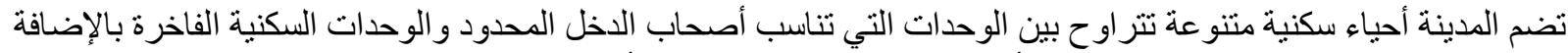

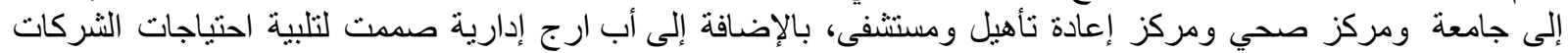

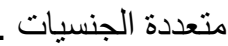

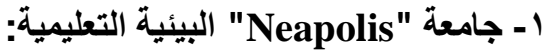

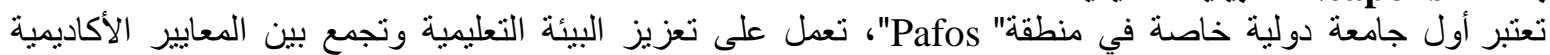

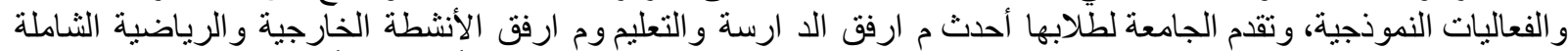

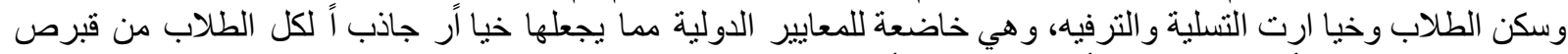

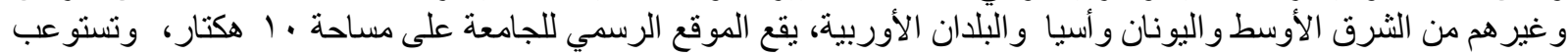

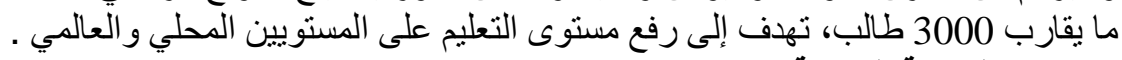

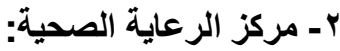

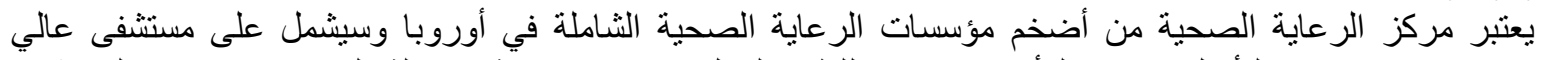

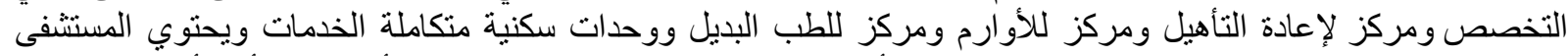

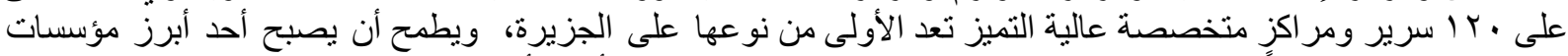

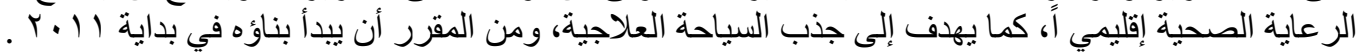




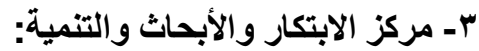

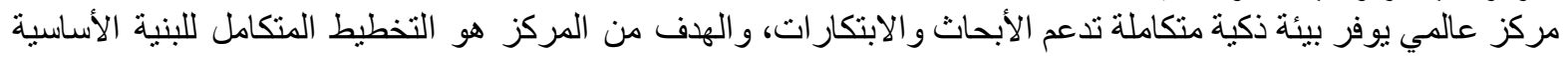

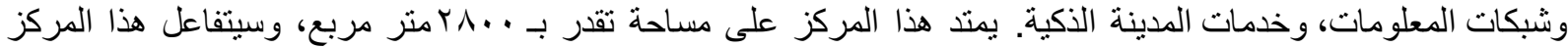

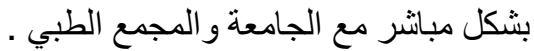

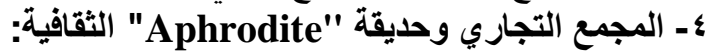

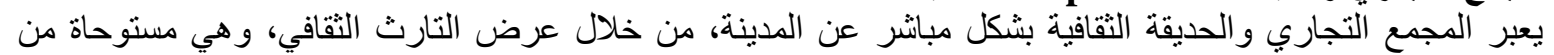

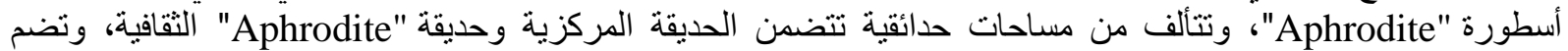

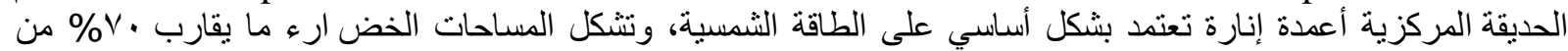

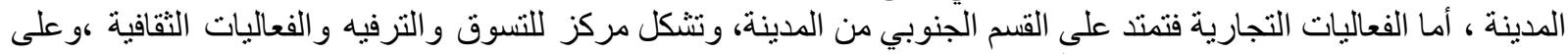

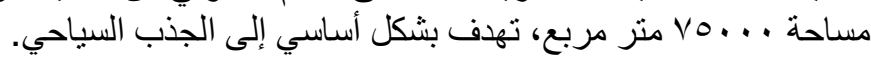

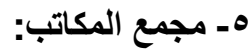
تضم المدينة مركز دولي أ للأعمال يمثل وسط المدينة الجديدة، صمم بناء على معايير التنمية المستدامة، لتلبية احتياجات الثركات متعددة الجنسيات ، ويقع بالمنطقة الجنوبية الغربية للمدينة.

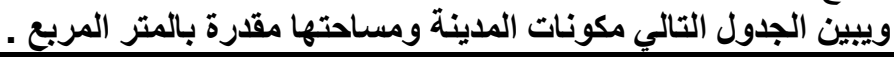

\begin{tabular}{|c|c|}
\hline المساحة بالمتر المربع & مكونات مدينة" نيابوليس" \\
\hline 12000 & المشفى \\
\hline 19000 & 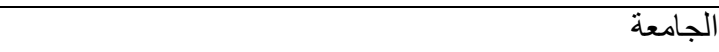 \\
\hline 37140 & المجمع التجاري \\
\hline 6500 & الفندق \\
\hline 2800 & مركز التنمية والبحث و الابتكار \\
\hline 15000 & مجمع المكاتب \\
\hline 20000 & الفر اغات التجارية \\
\hline 1265 & الساحة المركزية \\
\hline 360332 & المباني السكنية الفاخرة \\
\hline 18960 & السكن منخفض التكلفة \\
\hline 1500 & الخدمات التجارية \\
\hline 3500 & الفعاليات الترفيهية و الرياضية \\
\hline 22200 & سكن المسنين وذوي الاحتباجات الخاصة \\
\hline 520098 & المساحة الكلية \\
\hline
\end{tabular}

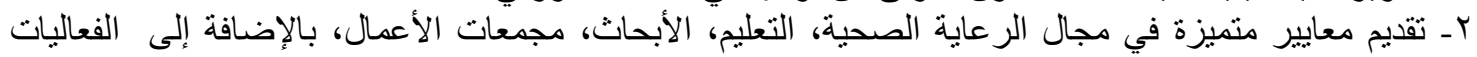

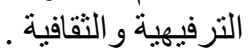
كـ ــ دعم التعليم و الأبحاث و الابتكار لتكوين مجتمع يعتمد على المعرفة .

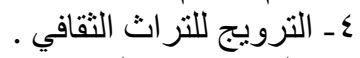
هـ خلق فرص عمل جديدة.

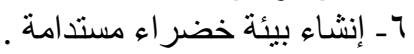

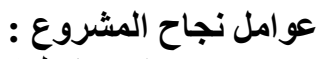

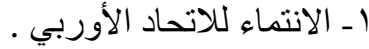

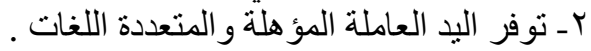

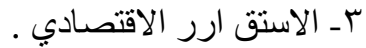
ع ـ البنية التحتية وشبكات الاتصن الاتصالات المتقدمة . هـ أهم الوجهات السياحية، حيث ويصات "الاتهل عدد السياح سنوي اً إلى 2.2 مليون سائح وثلث هذا العدد يتوجه إلى منطقة .Pafos" 
الــ الموقع المركزي لمدينة"Neapolis"مع سهولة الوصول من المنطقة السياحية في Pafos.

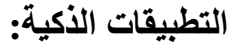

الظمة المر اقبة المنزلية: وتتمثل في نظام مركزي لإدارة المنزل، وتعمل على توفير الأمن المنزلي من خلال مر اقبة

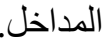

. العناية الصحية عن بعد. الصدية.

• أنظمة التحكم بالطاقة المنزلية: تتكون من شبكات المر افق الذكية التي تستخدم مصادر الطاقة الذكية،

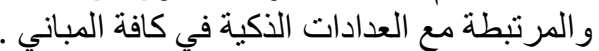

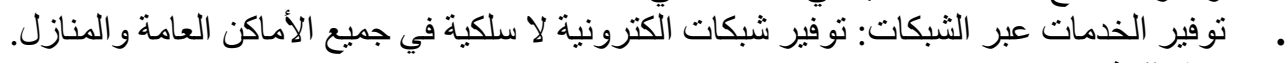

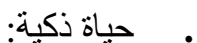

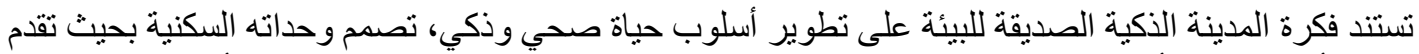

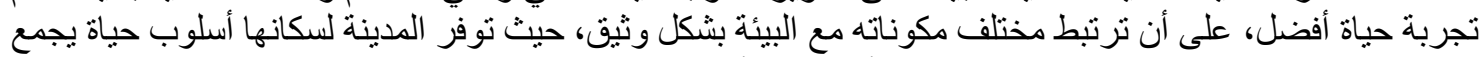

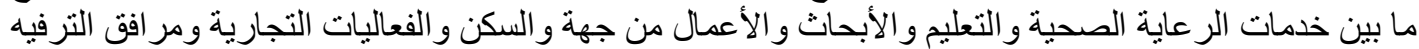

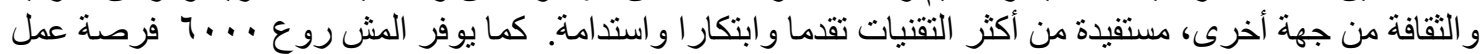

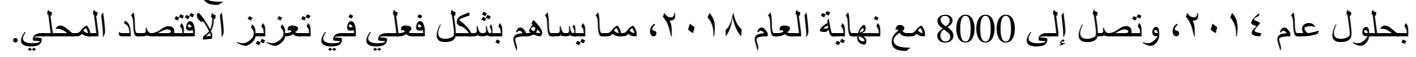

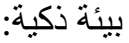

إعادة التدوير : تنقية المياه ، معالجة مياه الصرف الصحي ، إدارة المخلفات الصلبة ، و الطاقة المتجددة.

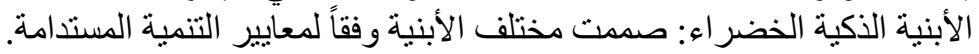

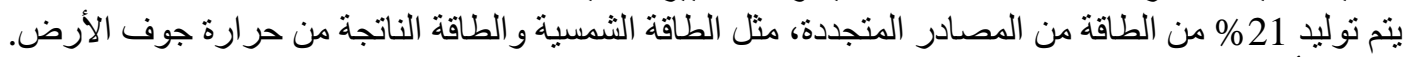
التحكم بأنظمة الري في الحدائق .

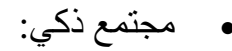

تستخدم المدينة استر اتيجيات التنمية الابداعية الأكثر تطور ا، لإنشاء مجتمع ذكي ومستدام.

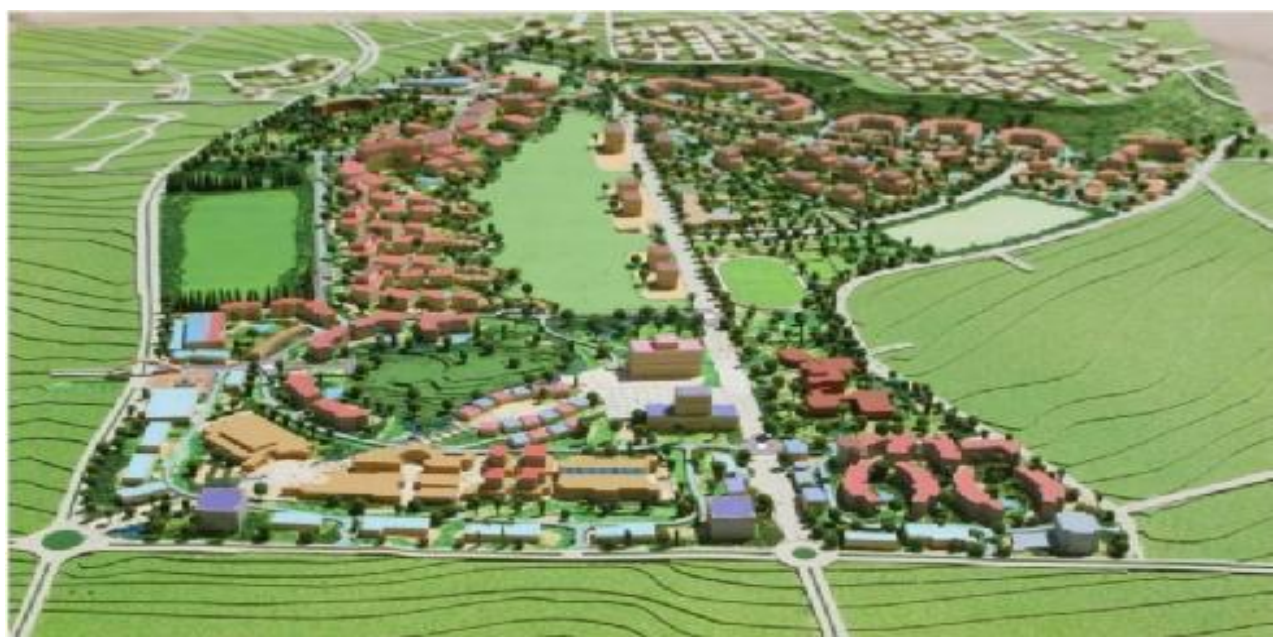

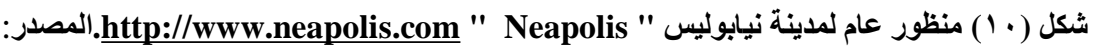

المدينة محل الار اسة

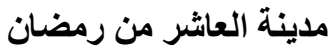

مدينة العاثر من رمضنان هي مدينة تقع بمحافظة الثرقية بمصر وتثبع هيئة المجتمعات العمرانية، وتعتبر من مدن الجيل

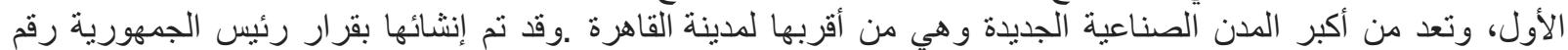

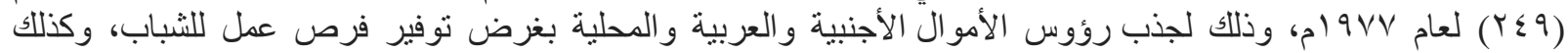

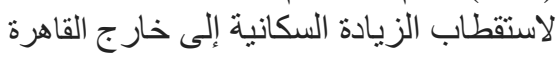




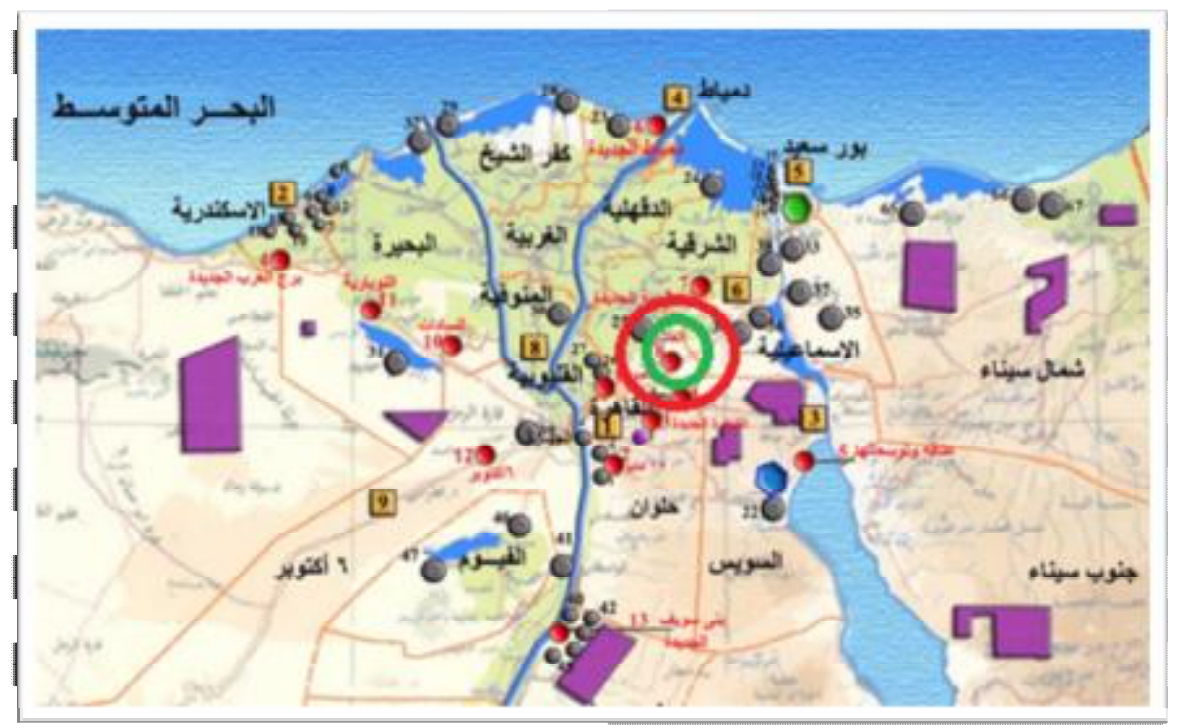

https://www.google.com.eg شكل (1 11 ) موقع مدينة العاشر من رمضان المصدر: تقع المدينة على طريق القاهرة / الإسماعيلية الصحر اوى عند الكم ؟؟؛ ، وتبعد عن مدينة بلبيس حو الى • ب كم ، ويمتاز موقعها بأنه ملتقى منطقة قناة السويس ومحافظات الوجه البحة البحرى ومدينة القاهرة .((هيئة المجتمعات العمر انية الجديدة) المخطط العام للمدينة

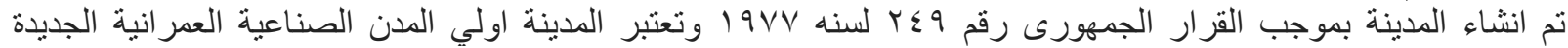

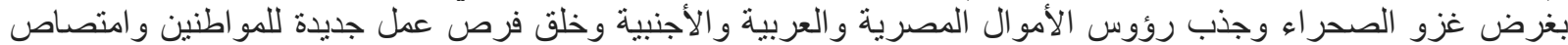

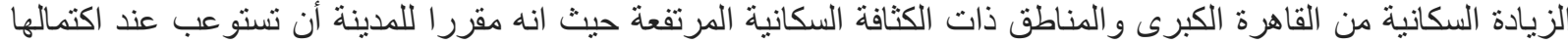

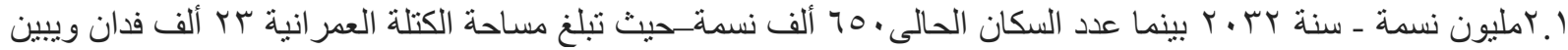
الثكل التالي الهيكل التخطيطي (التقسيم الوظيفي) واستعمالات الار اضي الني بال لمدينة

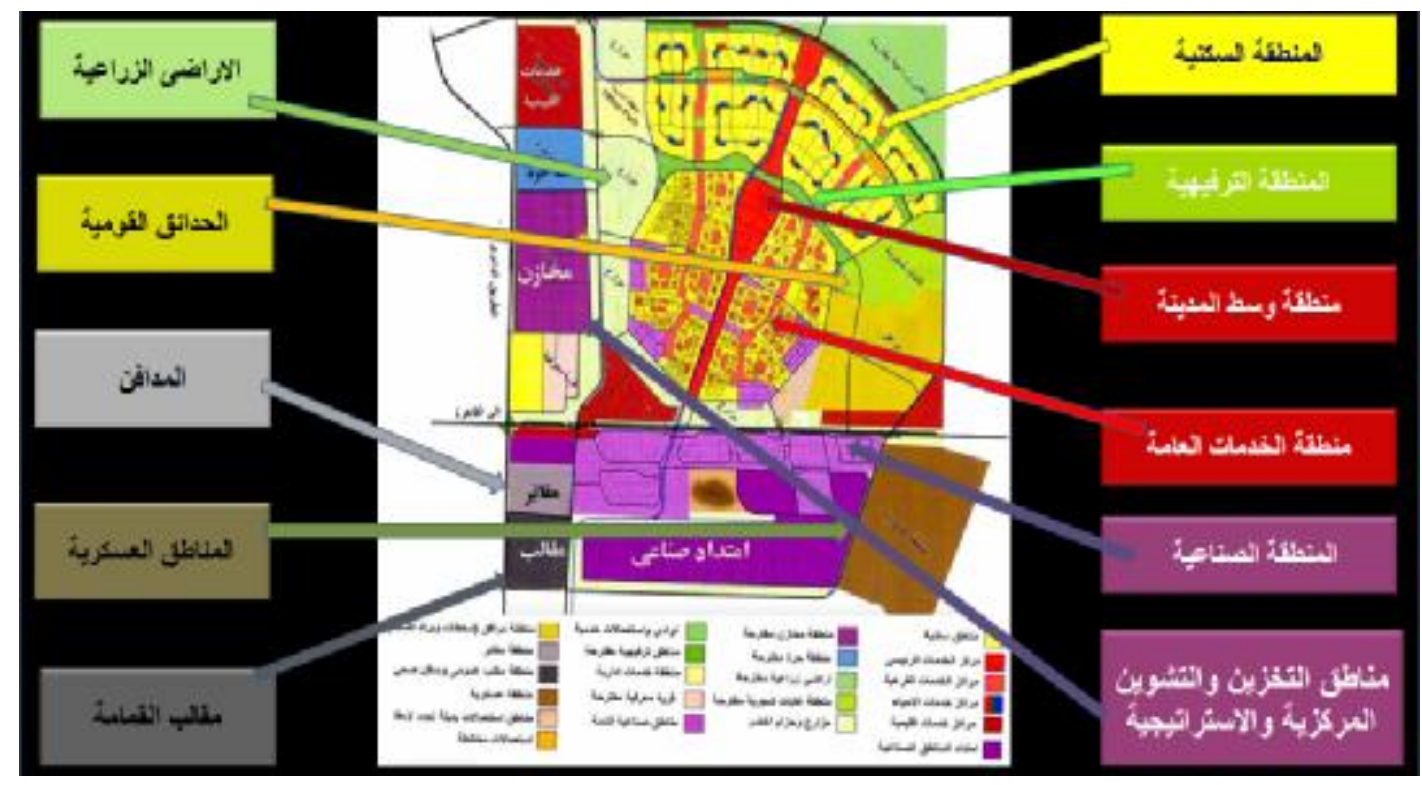

شكل (11) موقع مدينة العاشر من رمضان المصدر: الباحث 
وتعاني المدينة من بعض أوجه القصور، مما أدى إلى فثل المدينة في اجتذاب العدد المستهذف من السكان وتثثير الدراسات

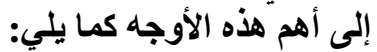

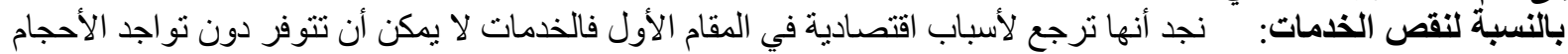

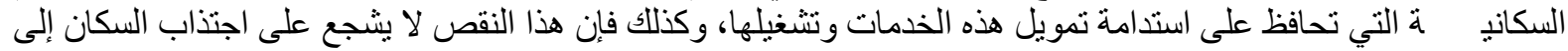

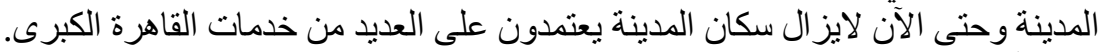

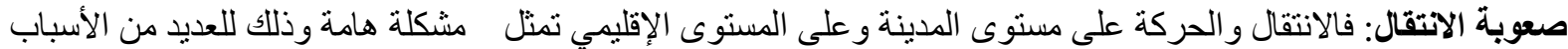

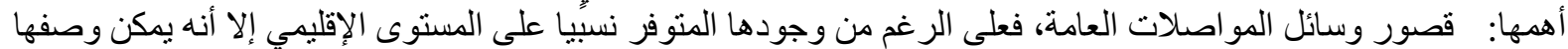

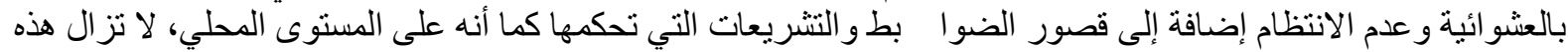

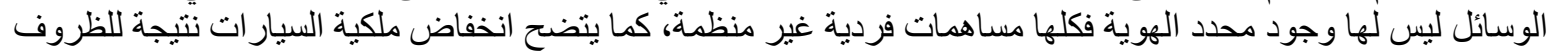

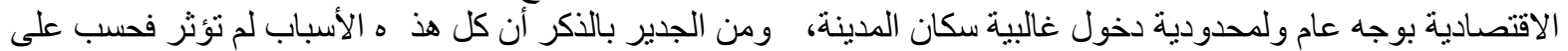

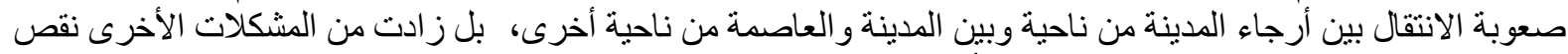

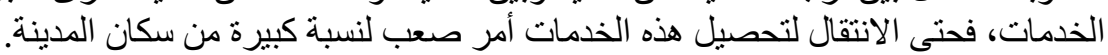

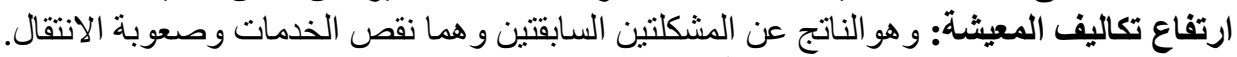

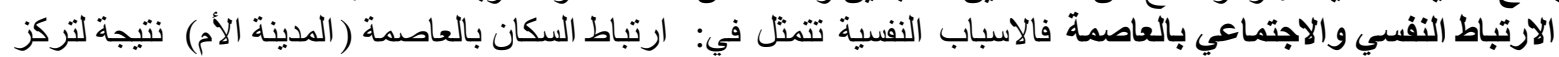

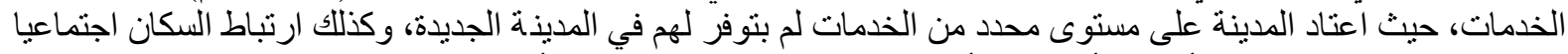

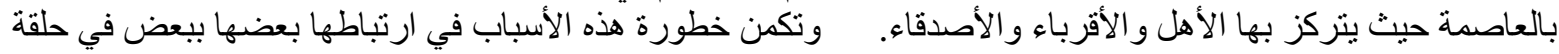

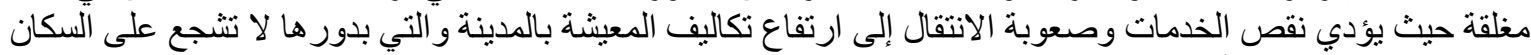

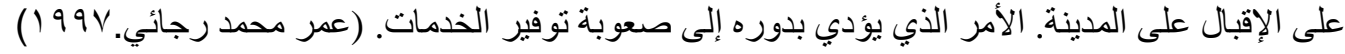

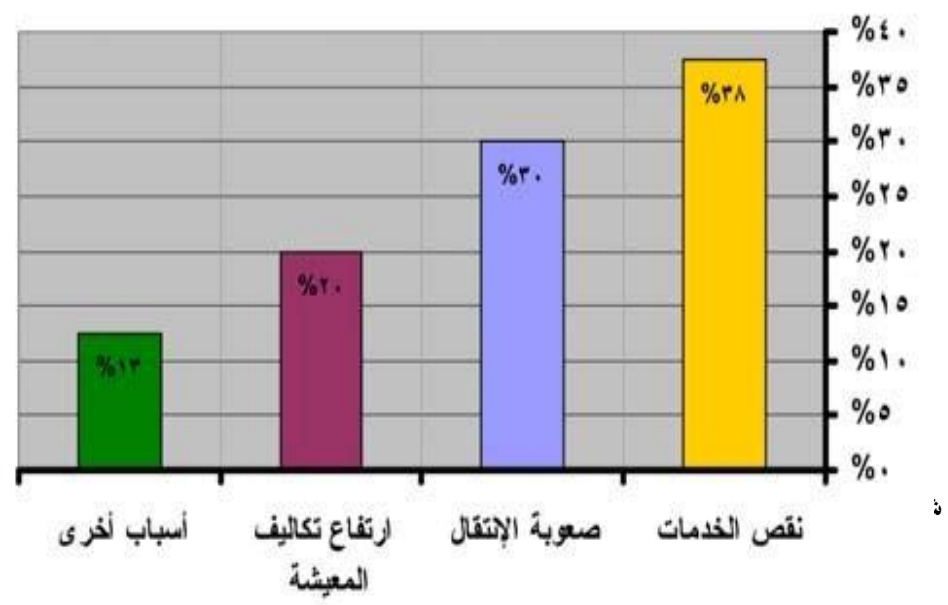

خطة التطوير المقترحة: - م

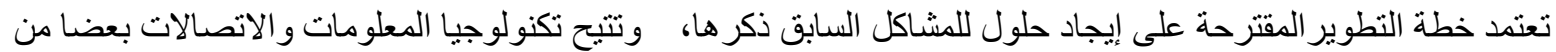

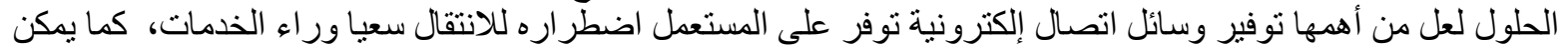

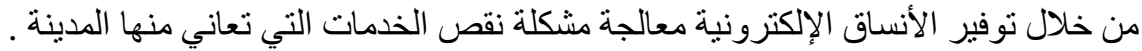

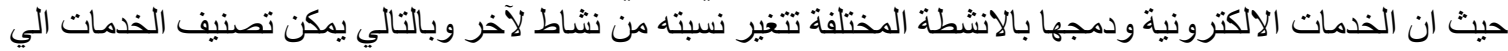

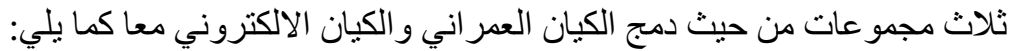

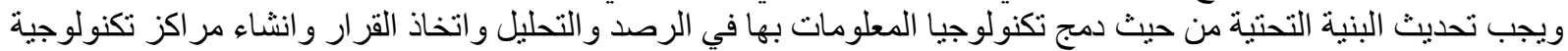

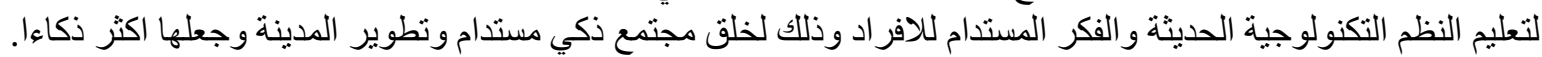

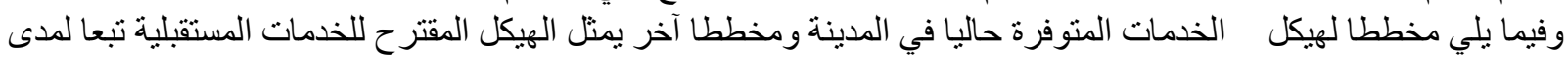
إمكانية توفير ها إلكترونيا 


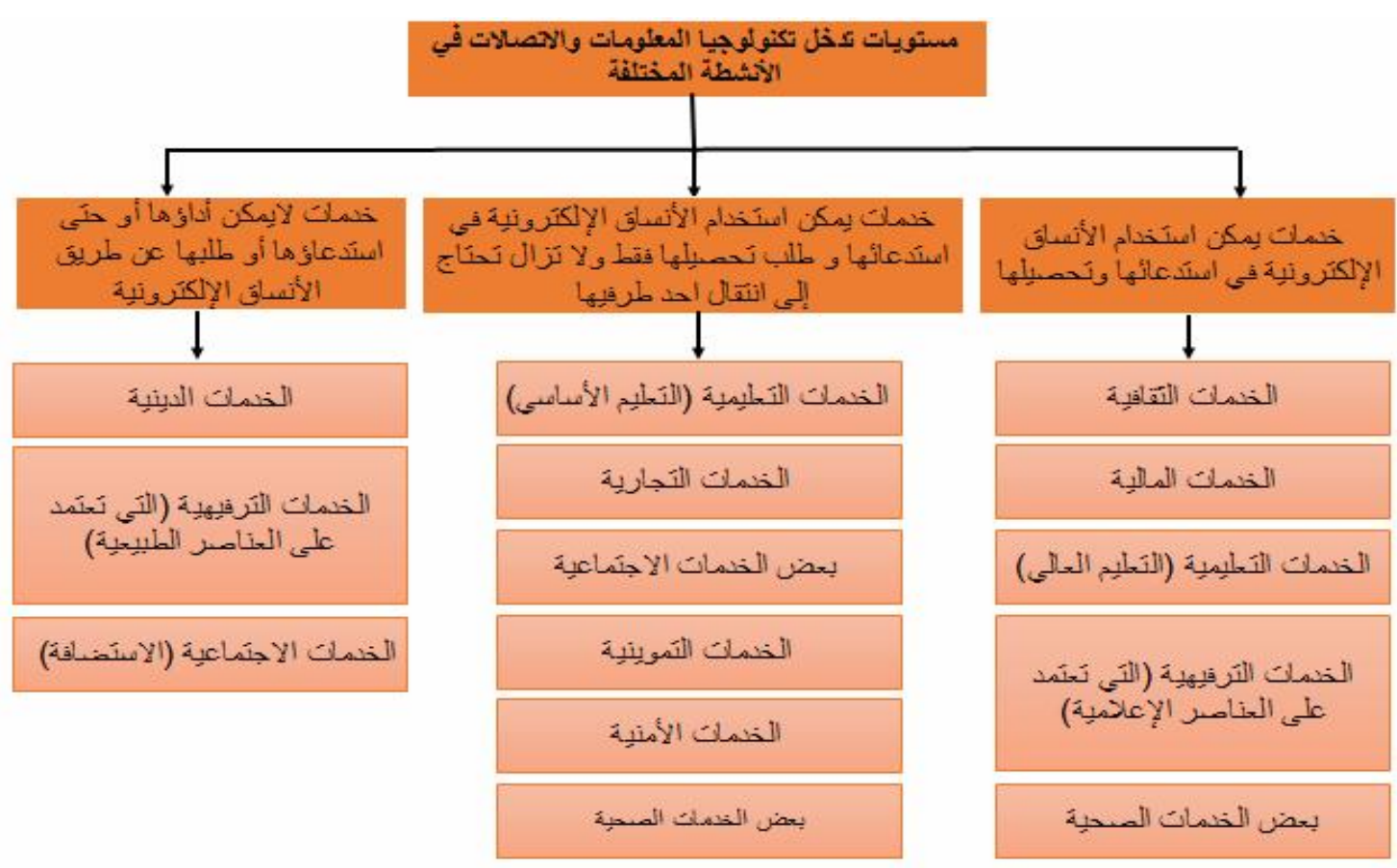

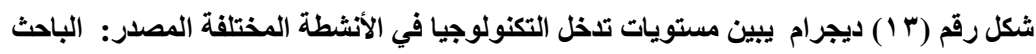


دور الثورة التكنولوجية في تتمية المدن المصرية وظهور أنو اع جديدة من المدن (حالة دراسية مدينة العاثر من رمضان)
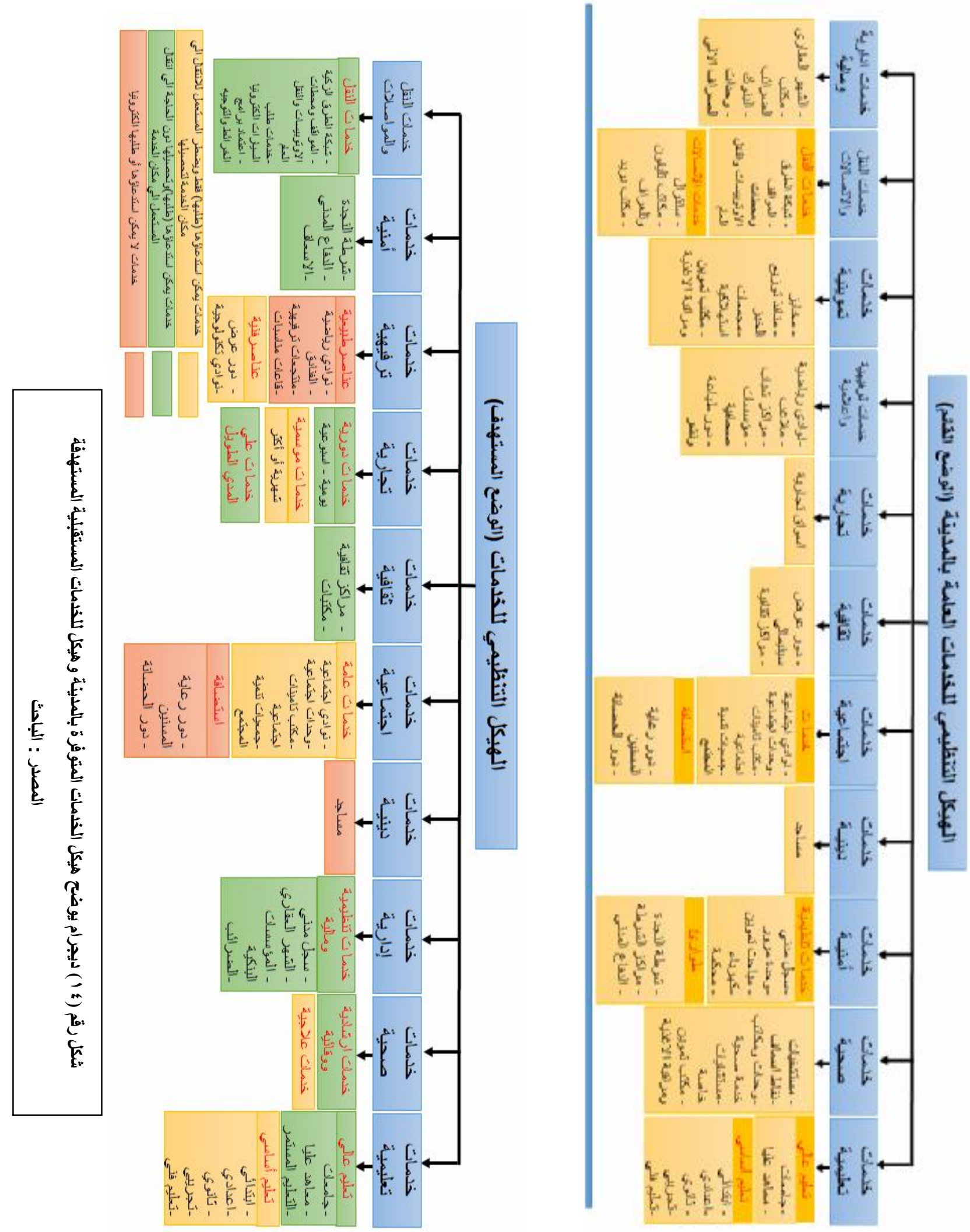


$$
\text { التوصيات : }
$$

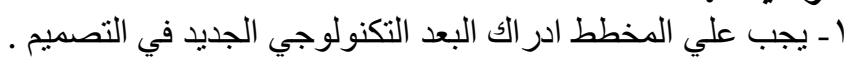

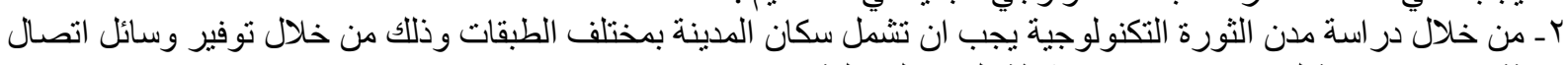

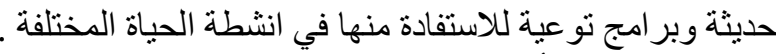

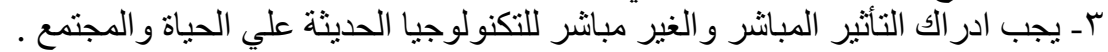

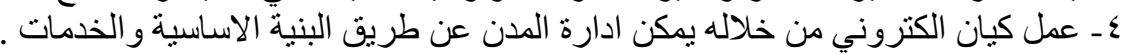

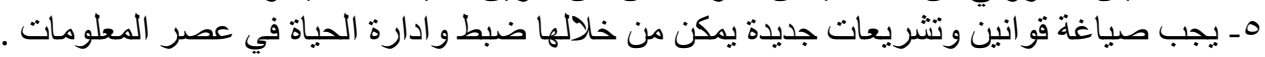

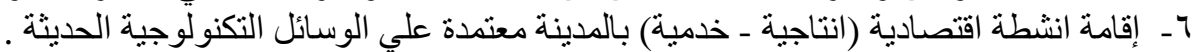

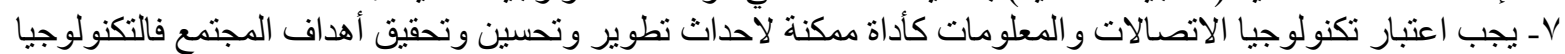

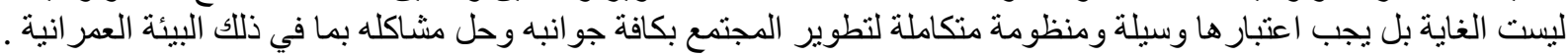

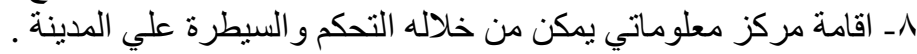

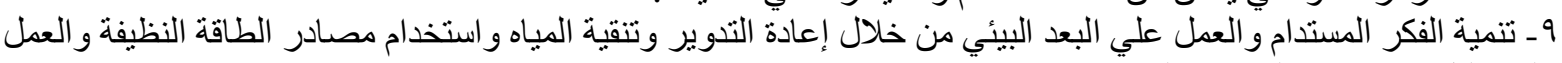

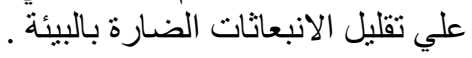

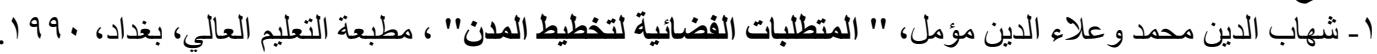

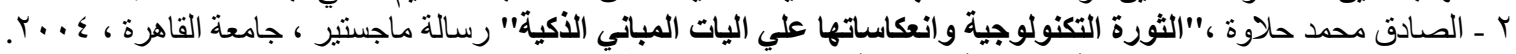

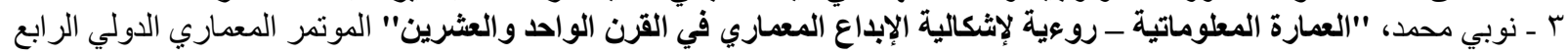

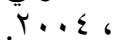

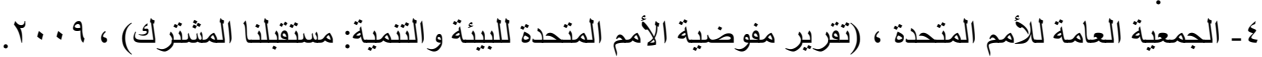

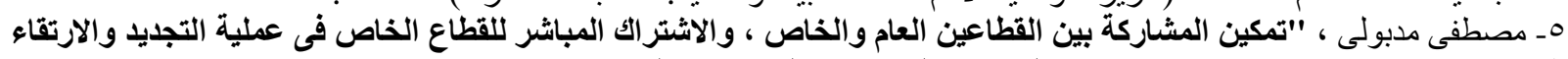

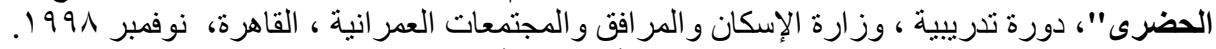

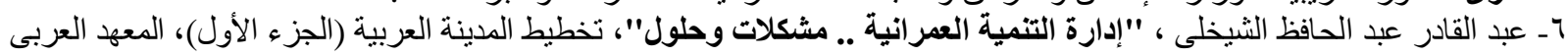

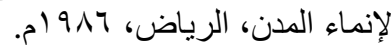
لإــ محمد أنور زايد، " تخطيط المدان في حقبة تكنولوجيا المعلومات"، رسالة ماجستير غير منشورة، كلية الهندسة، جامعة القاهرة، الجيزة، 2003.

$$
\text { ^ــعمر محمد رجائي، "دور النقل والمواصلات في تنمية المدن الجديدة"، رسالة ماجستير غير منشورة، كلية الهندسة }
$$
- - مامعة القاهرة، 1997.

9- Gaffrey,R.J."Building Performance and Occupant Productivity",4th Worled congress.Hong Kong, 1990

10- Adie, T. and P. Robert “GETTING SMARTER ABOUT SMART CITIES”. Washington, ESADE $(T \cdot 1 \xi)$.

11- United Nations World Urbanization Prospects: the 2014 revision, highlights (UN Department of Economic and Social Affairs), 2014.

12- André Sorensen, "Towards Sustainable Cities", (Ashgate Publishing, 2014).

13- Moss M. \& Townsend A., "How telecommunications systems are transforming urban spaces".

Cities in the Telecommunication Age, UK., 2000.

14 - IBM Center for Economic Development analysis.

15 - Wheeler, J. et al. "Cities in the Telecommunication Age", Routledge, London, 2000.

-http://www.informationcity.org/about/modeling.htm

16- Stefan Probst, "Brief introduction to e-commerce", Vitnam, 1999

17- Abdoullaev, A.” The Smart Eco Island: i-Cyprus 2020 Neapolis Smart Eco City",

http://www.neapolis.com.

18- Narushige Shiode,http://www.geog.ucl.ac.uk/ nshiode/vcgis98/alpha.html

19- http://s.amazonaws.com/hlp-section-images/NeapolisMap

20- مدينة_مستدامة//ttps://ar.wikipedia.org/wiki

21- http://s.amazonaws.com/hlp-section-images/NeapolisMap

22 - (هيئة المجتمعات العمر انية الجديدة) http:/www.newcities.gov.eg/know cities/Tenth Ramadan/default.aspx 